\title{
Uma Proposta de Unidade de Ensino Potencialmente Significativa para Ensinar Física de Partículas por meio de Jogos de Cartas
}

\author{
A Proposal of a Potentially Meaningful Teaching Unit to Teach Particle \\ Physics Using Card Games
}

\author{
RAFAEL TERESO DE JESUS*1, RONNI GERALDO GOMES DE AMORIM ${ }^{\dagger 2}$ \\ ${ }^{1}$ Secretaria de Educação do Estado de Minas Gerais \\ ${ }^{2}$ Instituto de Física. Universidade de Brasília, Campus Darcy Ribeiro, Asa Norte, Brasília, \\ DF, CEP 70900-000
}

\section{Resumo}

O presente trabalho apresenta os resultados da produção e aplicação de uma sequencia didática fundamentada sob o formato de uma Unidade de Ensino Potencialmente Significativa (UEPS). O desenvolvimento e a aplicação das atividades presentes neste trabalho deram-se a luz da Teoria da Aprendizagem Significativa de David Ausubel, preconizando que aquilo que o aluno já sabe é a componente mais importante que sustenta o processo de aprendizagem. As partículas elementares foram tomadas como suporte para as situações-problema, atividades desenvolvidas e aplicação dos jogos de cartas que possibilitaram analisar o modelo padrão, sua constituição, os conceitos físicos envolvidos e discutir temas relacionados com a formação dos hádrons. A análise dos dados obtidos reforça a necessidade de inserir tópicos de Física Moderna e Contemporânea no Ensino Médio através de iniciativas alternativas ao ensino tradicional desses tópicos e reafirma a potencialidade da aplicação de jogos na educação.

Palavras-chave: Ensino de Física. Aprendizagem significativa. UEPS. Modelo padrão. Partículas elementares. Jogos de cartas.

\footnotetext{
*raphaeltereso@hotmail.com
}

†ronniamorim@gmail.com 


\begin{abstract}
The present work presents the results of the production and application of a didactic sequence based in the form of a Potentially Significant Teaching Unit (UEPS. The development and application of the activities present in this work gave rise to David Ausubel Significant Learning Theory, suggesting that what the student already knows is the most important component that sustains the learning process. The elementary particles were taken as support for problem situations, developed activities and application of card games that made it possible to analyze the standard model, its constitution, the physical concepts involved and discuss themes related to the formation of hadrons. The analysis of the obtained data reinforces the need to insert topics of Modern and Contemporary Physics in High School through alternative initiatives to the traditional teaching of these topics and reaffirms the potential of the application of games in education.
\end{abstract}

Keywords: Physics teaching. Meaningful learning. UEPS. Standard model. Elementary particles. Card games.

\title{
I. INTRODUÇãO
}

A ciência é uma manifestação cultural com grande poder de transformação na sociedade. Isto se deve ao fato de que ela contribui para moldar o modo de vida das pessoas. Seu desenvolvimento está fortemente relacionado com o desenvolvimento da tecnologia, das telecomunicações, dos meios de transporte, da produção de alimentos e medicamentos, dentre outros. A ciência configura-se assim, como forte impulsionador da globalização, contribuindo para uma melhor compreensão do mundo.

Neste contexto, a aprendizagem em ciência é importante ao permitir a formação de um cidadão contemporâneo, atuante, solidário, e com instrumentos que lhe permitam compreender, intervir e participar de forma significativa na realidade. Ela se ocupa não somente de investigar os fenômenos que nos rodeiam, mas também, em explica-los e fornecer teorias plausíveis que se aceitas possam quantificar e descrever como ocorrem. Nesse sentido, as Orientações Educacionais Complementares aos Parâmetros Curriculares Nacionais $(\mathrm{PCN}+)$ apontam que:

A Física deve apresentar-se, portanto, como um conjunto de competências específicas que permitam perceber e lidar com os fenômenos naturais e tecnológicos, presentes tanto no cotidiano mais imediato quanto na compreensão do universo distante, a partir de princípios, leis e modelos por ela construídos.

(BRASIL, 2002, p. 59)

Para tanto, faz-se necessário que o ensino de Física no Ensino Médio deixe de se basear na simples memorização de equações ou reprodução mecânica de procedimentos, conscientizando-se de que é necessário lhe dar um significado, apontando seu sentido no momento do aprendizado. 
Para que esse processo de ensino aprendizagem faça sentido para o aluno, é necessário que ele seja baseado em um diálogo constante entre alunos e professores, onde o conhecimento deve ser o ponto central das ações. Para atingir tal objetivo é necessário ainda, considerar objetos, coisas e fenômenos que estejam inseridos no cotidiano dos estudantes, seja próximo, como celulares, computadores ou televisores, ou que seja fruto de sua curiosidade, como o cosmos e o mundo subatômico. Dessa forma, devem ser sempre privilegiadas ações que possibilitem essa interação.

Sobre os temas e competências que possibilitem tal interação, os PCN+ apontam que é sempre possível tratar qualquer tema em qualquer uma das séries do Ensino Médio. No entanto, alguns temas são mais adequados para o desenvolvimento de determinadas competências. Como é o caso da Física Moderna, uma vez que apresenta elementos que permitem realizar sínteses mais consistentes.

Quanto ao ensino da Física Moderna e Contemporânea no Ensino Médio, os PCN+ apontam que:

Alguns aspectos da chamada Física Moderna serão indispensáveis para permitir aos jovens adquirir uma compreensão mais abrangente sobre como se constitui a matéria, de forma que tenham contato com diferentes e novos materiais, cristais líquidos e lasers presentes nos utensílios tecnológicos, ou com o desenvolvimento da eletrônica, dos circuitos integrados e dos microprocessadores. A compreensão dos modelos para a constituição da matéria deve, ainda, incluir as interações no núcleo dos átomos e os modelos que a ciência hoje propõe para um mundo povoado de partículas. Mas será também indispensável ir mais além, aprendendo a identificar, lidar e reconhecer as radiações e seus diferentes usos. $\quad$ (BRASIL, 2002, p. 70)

Os Parâmetros Curriculares Nacionais (PCNs) indicam a importância de uma inclusão efetiva da Física Moderna e Contemporânea (FMC) no currículo do Ensino Médio, que para Menezes (1996) visa à universalização ao acesso a essa intrigante área do conhecimento que se relaciona aos principais desenvolvimentos tecnológicos vivenciados atualmente pela sociedade.

Nesse sentido, a inserção da FMC no Ensino Médio é necessária para que os estudantes possam compreender os fenômenos ligados às situações vivenciadas por eles, contribuindo para o exercício pleno de sua cidadania. Para tanto, Terrazzan (1992) aponta que:

A tendência de atualizar o currículo de Física justifica-se pela influência crescente dos conteúdos contemporâneos para o entendimento do mundo criado pelo homem atual, bem como a necessidade de formar um cidadão consciente e participativo que atue nesse mesmo mundo.

(TERRAZAN, 1992, p. 210)

Sendo assim, um dos objetivos da FMC é discutir o conceito de Modelo Padrão ${ }^{1}$ das

${ }^{1}$...é a mais sofisticada teoria matemática sobre a natureza. Apesar da palavra modelo em seu nome, o 
Partículas Elementares ${ }^{2}$. Sobre esse assunto, de acordo com Moreira (2004):

Uma visão introdutória ao assunto partículas elementar e interações fundamentais podem ser abordadas, de maneira acessível, de forma a transmitir aos alunos a ideia de um assunto excitante, colorido, estranho e charmoso.

(MOREIRA, 2004, p. 10)

Procurando incentivar o ensino e divulgação da FMC no Ensino Médio, mais especificamente da Física de Partículas, bem como fornecer aos professores um material complementar para auxiliar suas aulas, buscou-se desenvolver a presente pesquisa considerando a confecção e aplicação de jogos de cartas, a luz da Teoria da Aprendizagem Significativa de David Ausubel $^{3}$, tendo como objetivo a assimilação dos conceitos de Física de Partículas e Interações Fundamentais.

Como objetivo geral buscou-se desenvolver e aplicar uma Unidade de Ensino Potencialmente Significativa $^{4}$ (UEPS) de acordo com as definições de Moreira (2011). De forma específica, os objetivos foram: levantar os conhecimentos prévios relacionados à Física de Partículas; produzir jogos de cartas relacionáveis aos conhecimentos prévios; aplicar e avaliar a sequência didática.

A sequência didática seguiu uma organização com o intuito de fornecer condições para que de acordo com Moreira e Masini (2001), a aprendizagem significativa ocorresse em detrimento da aprendizagem dita mecânica e sem significado. Para tanto, buscou-se formas de relacionar os conceitos de Física de Partículas e Interações Fundamentais, possibilitando assim, que o significado dos conceitos pudesse ser assimilado de forma efetiva.

\section{Fundamentação TeÓRICA}

\section{David Ausubel e a teoria da aprendizagem significativa}

Visou-se no presente trabalho, elaborar, aplicar e avaliar uma Unidade de Ensino Potencialmente Significativa - UEPS, que é uma sequência didática difundida por Moreira (2011), onde ele pauta-se, na Teoria da Aprendizagem Significativa de David Ausubel.

O conceito de aprendizagem significativa surge da corrente cognitivista que enfatiza o processo de cognição, através do qual a pessoa atribui significados à realidade em que se encontra. Essa corrente preocupa-se com o processo de compreensão, transformação, armazenamento e uso da informação envolvido na cognição e procura regularidades nesse

Modelo Padrão é uma teoria compreensiva que identifica as partículas básicas e especifica como interagem. (MOREIRA, 2009, p. 1306-1).

2 ...no sentido de não possuírem estrutura interna. Partículas que têm estrutura interna são chamadas de hádrons; são constituídas de quarks: bárions quando formadas por três quarks ou três antiquarks, ou mésons quando constituídas por um quark e um antiquark. (MOREIRA, 2009, p. 1306-1).

3 ... é aquela em que ideias expressas simbolicamente interagem de maneira substantiva e não-arbitrária com aquilo que o aprendiz já sabe. (MOREIRA, 2012, p. 2).

${ }^{4}$ São sequências didáticas fundamentadas teoricamente, voltadas para a aprendizagem significativa, não mecânica, que podem estimular a pesquisa aplicada em ensino, aquela voltada diretamente à sala de aula. (MOREIRA, 2011, p. 2). 
processo. Nessa corrente, situam-se autores como Brunner, Piaget, Ausubel, Novak e Kelly. Alguns deles são construtivistas com ênfase na cognição (Brunner, Piaget, Ausubel e Novak), ou enfatizam o afetivo (Kelly e Rogers), (OSTERMANN e CAVALCANTI, 2011).

A aprendizagem significativa nada mais é que um processo através do qual uma nova informação se relaciona de maneira não arbitrária e substantiva a um aspecto relevante da estrutura cognitiva do indivíduo (MOREIRA, 2011). Segundo Ausubel, este tipo de aprendizagem é, por excelência, o mecanismo humano para adquirir e reter a vasta quantidade de informações de um corpo de conhecimentos. Ausubel destaca o processo de aprendizagem significativa como o mais importante na aprendizagem escolar (OSTERMANN e CAVALCANTI, 2011).

A ideia mais importante da teoria de Ausubel e suas implicações para o ensino e a aprendizagem podem ser resumidas na seguinte proposição:

Se tivesse que reduzir toda a psicologia educacional a um só princípio, diria o seguinte: o fator isolado mais importante que influencia a aprendizagem é aquilo que o aprendiz já sabe.

(AUSUBEL et al, 1980, p.137)

Para Ausubel (1980), o armazenamento de informações na mente é altamente organizado, formando uma hierarquia conceitual onde elementos mais específicos são ligados a conceitos, ideias e proposições mais gerais. Já a aprendizagem mecânica é aquela na qual a nova informação é armazenada de maneira arbitrária e literal, não interagindo com aquela já existente na estrutura cognitiva e pouco contribuindo para sua elaboração e diferenciação (OSTERMANN e CAVALCANTI, 2011).

\section{I.1 Conceito subsunçor}

De acordo com Moreira e Masini (2001), supondo que a aprendizagem significativa deva ser preferida em relação à aprendizagem mecânica, e que isso pressupõe a existência prévia de conceitos subsunçores, o que fazer quando estes não existem? Como pode a aprendizagem ser significativa nesse caso? De onde vêm os subsunçores? Como se formam? Essas perguntas serão respondidas ao longo do trabalho.

De acordo com Gonzales e Rosa (2014) apud (AUSUBEL, 1980), o foco da Teoria da Aprendizagem Significativa são as modificações sofridas pela estrutura cognitiva do aluno quando uma nova informação se relaciona com uma informação já existente, conhecida como subsunçor. Ausubel define a estrutura cognitiva como uma estrutura de ideias já existentes (conhecimentos) com determinado grau de clareza, estabilidade e diferenciação.

O termo subsunçor é uma denominação dada por Ausubel ao conjunto organizado de conceitos, proposições ou ideias já existentes na estrutura cognitiva que servem de âncora para as novas informações contidas no material instrucional.

Ainda sobre o termo subsunçor:

O "subsunçor"é um conceito, uma ideia, uma proposição já existente na estrutura cognitiva, capaz de servir de "ancoradouro a uma nova informação de modo que ela adquira, assim, significado para o indivíduo: a aprendiza- 
gem significativa ocorre quando a nova informação "ancora-se"em conceitos relevantes preexistentes na estrutura cognitiva.

(OSTERMAN e CAVALCANTI, 2011, p. 34)

Os subsunçores são de suma importância na teoria, uma vez que a aquisição do conhecimento depende da maneira pela qual a informação do material instrucional será relacionada com os subsunçores presentes na estrutura cognitiva. Quando as novas informações são apresentadas, interage com os subsunçores existentes e, em decorrência deste processo, a estrutura cognitiva é modificada de forma que o indivíduo passa a resolver problemas mais gerais que não conseguia anteriormente.

Em contrapartida, quando a nova informação é apresentada ao aprendiz sem relação com os subsunçores, ou ainda que ela se relacione de forma superficial e arbitrária, ocorre outra forma de aprendizagem, denominada aprendizagem mecânica.

Armazenar de maneira arbitrária significa associar o novo conhecimento a qualquer aspecto da estrutura cognitiva do aprendiz, não levando em consideração os aspectos mais relevantes que poderiam servir de ancoradouro.

\section{I.2 Condições para que ocorra a aprendizagem significativa}

Para que ocorra a aprendizagem significativa, Moreira (2001) apud (AUSUBEL, 1968 p. 37 - 41), aponta duas condições: a primeira relacionada aos conceitos apresentados e a segunda, relacionada fundamentalmente ao aluno. São elas: a organização de um material potencialmente significativo e a intencionalidade do aluno para aprender de forma significativa.

a) o material a ser aprendido seja potencialmente significativo para o aprendiz, ou seja, relacionável a sua estrutura de conhecimento de forma nãoarbitrária e não-literal (substantiva); b) o aprendiz manifeste uma disposição de relacionar o novo material de maneira substantiva e não-arbitrária a sua estrutura cognitiva.

(MOREIRA, 2001, p. 23)

Nesse sentido, para que um material seja considerado potencialmente significativo, deverá considerar, em sua elaboração, aquilo que o estudante já sabe e também o que ele deve aprender:

(...) organizar um material de ensino potencialmente significativo requer que a relação entre a natureza desses dois conhecimentos a estrutura lógica do conhecimento em si e a estrutura psicológica do conhecimento do aluno seja considerada.

(LEMOS, 2011, p. 30)

Em consonância com a apresentação do material potencialmente significativo, deve existir a intencionalidade do estudante em aprender de forma significativa. De acordo com Moreira (2011), para que a aprendizagem significativa ocorra é necessário que o aprendiz manifeste intenção em querer aprender significativamente, sem predisposição para aprender, 
o que geralmente ocorre é a aprendizagem mecânica, neste tipo de aprendizagem o conceito novo não interage com os subsunçores presente na estrutura cognitiva, não conseguindo explicar, transferir ou aplicar este conhecimento em outra situação, porque não ocorreu compreensão, apenas memorização.

Diante das condições apresentadas para que ocorra a aprendizagem significativa, vale ressaltar que a Unidade de Ensino Potencialmente Significativa apresentada nessa pesquisa pautou-se às condições apontadas por Ausubel e apresentadas por Moreira (2011) e Lemos (2011). Nesse sentido, utilizou-se um jogo de cartas construído pelo pesquisador como material de ensino potencialmente significativo e verificou-se a intencionalidade dos alunos em aprender, no instante em que aceitaram e se mostraram entusiasmados em participar da referida pesquisa, onde se considerou na elaboração e apresentação das atividades propostas, a relação entre o conhecimento a ser ensinado e os conhecimentos prévios dos alunos.

\section{I.3 A teoria da assimilação}

Para que o aluno aprenda significativamente os novos conceitos ensinados, é preciso que ocorram os processos de aquisição e organização dos significados na estrutura cognitiva (MOREIRA, 1999).

A esses processos que envolvem diretamente a modificação dos subsunçores e, consequentemente, da estrutura cognitiva, Ausubel (2003, p. 8) denomina assimilação. Segundo Ausubel, devido à dinâmica de aprendizagem, que é o produto da interação da nova informação com subsunçores já existentes, a nova estrutura cognitiva tende a se tornar cada vez mais estável para servir de âncora para informações futuras. A assimilação ocorre quando um novo conceito potencialmente significativo interage com um subsunçor ou um conjunto de subsunçores que servem de âncora para a nova informação. Enquanto ocorre a interação do novo conceito com o conceito já adquirido, ambos são modificados e dão origem a uma nova estrutura que, estará pronta para receber novos conceitos.

Para Roratto et al. (2011), a aprendizagem que não ancora o novo conhecimento em conceitos pré-existentes é considerada mecânica. Ausubel (2003), afirma que um conteúdo aprendido dessa forma não aumenta a substância ou a composição do conhecimento e, de forma geral, tem utilidade limitada, e seu propósito é poupar tempo e esforço.

Em contrapartida, quando conceitos prévios estão presentes na estrutura cognitiva e a aprendizagem se realiza por meio da assimilação de conceitos, aproxima-se da aprendizagem significativa ao passo que, nesse tipo de aprendizagem os novos significados são produto de uma interação ativa e integradora entre novos materiais de instrução e ideias relevantes da estrutura de conhecimentos existente do aprendiz (AUSUBEL, 2003, p. 43).

Esse processo de ancoragem é o aspecto essencial para a ocorrência da aprendizagem teorizada por Ausubel. Novas ideias se relacionam com o que o aprendiz já sabe e, como frutos dessa interação surgem os novos significados. Entretanto, é fundamental que essa ancoragem do novo conhecimento sobre o já existente nas estruturas cognitivas seja de forma não arbitrária e não literal (AUSUBEL, 2003).

Sobre esse processo de ancoragem não arbitrária, ainda de acordo com Ausubel (2003), este se refere a não alocação de um novo conhecimento de forma aleatória nas estruturas cognitivas; ele deve estar de alguma forma, interligado com o conhecimento âncora, como 
se fosse uma continuação, um detalhamento ou um refinamento dessa ideia inicial apresentada. O não literal implica no aluno conseguir resolver situações com pequenas variações comparando-se com aquela a que foi submetido no processo de aprendizagem inicial.

Em outras palavras, o aluno que aprende um conhecimento de forma literal por certo exemplo particular, não conseguirá resolver outros casos cujas estruturas não sejam as mesmas apresentadas nesse exemplo, não sendo capaz de transferir o conhecimento para outras situações.

Ainda sobre o processo de ancoragem, também chamado de subsunção, Ausubel defende que ele ocorre partindo de conceitos mais gerais e inclusivos, até atingir conceitos menos gerais e mais específicos, onde as informações novas e potencialmente significativas ancoramse, mais frequentemente, a ideias relevantes mais gerais e inclusivas na estrutura cognitiva do aprendiz.

[...] uma vez que a própria estrutura cognitiva tem tendência a ser organizada em termos hierárquicos, no que toca ao nível de abstração, generalidade e inclusão de ideias, a emergência de novos significados proposicionais reflete, de um modo geral, uma relação subordinada do novo material a ideias mais subordinantes na estrutura cognitiva.

(AUSUBEL, 2003, p. 93)

Dessa forma, na aprendizagem significativa ocorre uma organização hierárquica do conhecimento de forma que um novo conteúdo aprendido se ancora em conceitos mais gerais e inclusivos já existentes na estrutura cognitiva. Por sua vez, esse novo conhecimento poderá vir a se constituir como âncora para futuros aprendizados.

\section{I.4 Organizadores prévios e facilitadores programáticos}

Na perspectiva da aprendizagem significativa, é necessário que ocorra a presença de subsunçores, que são conceitos ou proposições claros, estáveis, diferenciados e especificamente relevantes na estrutura cognitiva.

No entanto, no caso de não se verificar a presença dos subsunçores, Ausubel (1968, p. 148) defende que a melhor estratégia é a utilização dos organizadores prévios. Para Moreira e Sousa (1996), estes são materiais introdutórios apresentados antes do material de aprendizagem em si, em um nível mais alto de abstração, generalidade e inclusividade. Moreira e Souza (1996) defendem ainda que sua principal finalidade é a de servir de elo entre o que o aprendiz já sabe e o que ele deve saber para que dessa forma o novo material possa ser aprendido de maneira significativa. Estes podem ainda ser considerados como um tipo de ancoradouro provisório.

De acordo com Moreira (2011), organizadores prévios podem ser adotados também para retomar significados obliterados (isso é perfeitamente possível se a aprendizagem foi significativa), para encontrar na estrutura cognitiva do aluno significados que existem, mas que por algum motivo não estão sendo usados há algum tempo. E principalmente para estabelecer relações entre ideias, proposições e conceitos já existentes na estrutura cognitiva e aqueles contidos no material de aprendizagem.

Os organizadores prévios, de fato, têm um efeito na aprendizagem e na retenção, mas 
pequeno. Quer dizer, como pontes cognitivas os organizadores prévios não têm muito valor instrucional, não são capazes de suprir a deficiência de subsunçores. Provavelmente, o maior potencial didático dos organizadores está na sua função de estabelecer, em um nível mais alto de generalidade, inclusividade e abstração, relações explícitas entre o novo conhecimento e o conhecimento prévio adequado do aluno para dar significado aos novos materiais de aprendizagem. Isto porque mesmo tendo os subsunçores adequados muitas vezes o aprendiz não percebe sua relacionabilidade com o novo conhecimento (Moreira, 2011).

No que tange à facilitação programática da aprendizagem significativa, Ausubel (1968, p. 152) propõe quatro princípios programáticos do conteúdo: diferenciação progressiva, reconciliação integrativa, organização sequencial e consolidação.

A diferenciação progressiva é o princípio segundo o qual as ideias e conceitos mais gerais e inclusivos do conteúdo da matéria de ensino devem ser apresentados no início da instrução e, progressivamente, diferenciados em termos de detalhe e especificidade (MOREIRA, 2011). Ausubel propõe esta organização programática do conteúdo baseado em duas hipóteses:

1) é menos difícil para o ser humano captar aspectos diferenciados de um todo mais inclusivo previamente aprendido do que chegar ao todo a partir de suas partes diferenciadas previamente aprendidas; 2) a organização do conteúdo de um corpo de conhecimento na mente de um indivíduo é uma estrutura hierárquica na qual as ideias mais inclusivas estão no topo da estrutura e, progressivamente, incorporam proposições, conceitos e fatos menos inclusivos e mais diferenciados.

(AUSUBEL, 1978, p. 190)

Nesse sentido, sendo a estrutura cognitiva organizada hierarquicamente e a aquisição do conhecimento ocorrendo mais facilmente se ocorrer de acordo com a diferenciação progressiva, nada mais natural do que programar a apresentação do conteúdo de maneira análoga, a fim de facilitar a aprendizagem significativa.

Dito isso, a programação do conteúdo deve não só proporcionar a diferenciação progressiva, mas também explorar, explicitamente, relações entre conceitos e proposições, chamar atenção para diferenças e similaridades relevantes e reconciliar inconsistências reais ou aparentes. Isso deve ser feito para se atingir o que Ausubel chama de reconciliação integrativa (MOREIRA, 2011).

A reconciliação integrativa é, então, o princípio programático segundo o qual a instrução deve também explorar relações entre ideias, apontar similaridades e diferenças importantes e reconciliar discrepâncias reais ou aparentes. A diferenciação progressiva e a reconciliação integrativa são processos da dinâmica da estrutura cognitiva, mas aqui estão sendo tratados como princípios programáticos instrucionais potencialmente facilitadores da aprendizagem significativa.

A organização sequencial, como princípio a ser observado na programação do conteúdo para fins instrucionais, consiste em sequenciar os tópicos, ou unidades de estudo, de maneira tão coerente quanto possível (observados os princípios da diferenciação progressiva e da reconciliação integrativa) com as relações de dependência naturalmente existentes na matéria 
de ensino.

O princípio da consolidação, por sua vez, é aquele segundo o qual insistindo-se no domínio (ou mestria) do que está sendo estudado, antes que novos materiais sejam introduzidos, assegura-se contínua prontidão na matéria de ensino e alta probabilidade de êxito na aprendizagem sequencialmente organizada. $O$ fato de Ausubel chamar atenção para a consolidação é coerente com sua premissa básica de que o fator isolado mais importante influenciando a aprendizagem é o que o aprendiz já sabe (MOREIRA, 2011).

\section{Os mapas conceituais de Joseph Novak}

O mapa conceitual foi criado na década de 1970, pelo professor da Universidade de Cornell, nos Estados Unidos e colaborador de Ausubel, Joseph D. Novak, como uma aplicação prática da teoria da aprendizagem significativa de Ausubel.

Um mapa conceitual é um diagrama que apresenta conceitos inter-relacionados formando uma estrutura conceitual. As relações existentes entre os conceitos são representadas por linhas que devem conter palavras-chave, cuja função é explicitar a natureza das mesmas. Cada conjunto formado por dois ou mais conceitos e uma ou mais palavra-chave forma uma proposição que evidencia o significado da relação conceitual representada (MOREIRA, 1997).

Os mapas conceituais apresentam uma organização hierárquica, partindo de um conceito mais amplo, mais inclusivo, para conceitos mais específicos, menos inclusivos. Na parte superior do mapa deve(m) estar o(s) conceito(s) mais inclusivo(s), mais geral(is). Na medida em que caminhamos verticalmente para baixo no mapa, encontramos conceitos mais específicos.

Para Cavellucci (2009), os mapas conceituais representam uma síntese de determinado tema. Nesse sentido, não existe uma única forma de representar um conhecimento ou uma estrutura conceitual, porque cada representação depende da estrutura cognitiva do autor da representação, da forma como ele percebe e representa o mundo, dos conceitos e relações escolhidos naquele contexto e do critério usado por ele para organizá-los.

Para a construção de um mapa conceitual é possível utilizar figuras geométricas (retângulo, elipse, círculo), no interior destas figuras são apresentados os conceitos. É possível ainda utilizar palavras e linhas conectoras entre elas. As linhas podem fornecer direção e sentido para determinadas relações entre conceitos ou até mesmo ajudar a guiar a leitura do mapa. Vale ressaltar que o mais importante é conseguir apresentar com clareza os significados atribuídos aos conceitos e as relações entre eles no contexto considerado.

O impacto visual do mapa conceitual não é o aspecto mais importante em sua elaboração, no entanto sua importância é ressaltada por Novak e Gowin (1988, p. 106), quando relata que um bom mapa conceitual é conciso e mostra as relações entre as ideias principais de modo simples e atraente, aproveitando a notável capacidade humana para representação visual.

Ainda sobre a construção propriamente dita do mapa, vale ressaltar que ela não deve necessariamente ocorrer de cima para baixo; conforme preconiza a concepção ausubeliana, onde os conceitos mais abrangentes, mais inclusivos, devem figurar na parte superior do mapa. Para tanto, é conveniente que fique claro o modo como os conceitos estão relacionados 
entre si. Com idas e vindas de cima para baixo e de baixo para cima no mapa, é importante explorarmos explicitamente as relações de subordinação e superordenação entre os conceitos (MOREIRA, 2006).

Como alerta final, é importante ressaltar que cada professor e cada aluno possuem suas preferências de aprendizagem e que, nem sempre, incluem representações visuais. Aqui as preferências de aprendizagem devem ser entendidas como o conjunto de preferências, que determina uma abordagem individual para aprender. Estas preferências variam ao longo da vida, de acordo com a situação de aprendizagem, seu conteúdo e a experiência do aprendiz, uma vez que, cada aprendiz tem sua história de vida, experiências de aprendizado bem sucedidas, e outras nem tanto. Este conjunto de experiências serve como pano de fundo para seus aprendizados futuros (CAVELLUCCI, 2003).

\section{Unidades de Ensino Potencialmente Significativas - UEPS}

A UEPS, segundo Moreira (2011), é uma sequência didática direcionada à aprendizagem significativa de conceitos e tópicos específicos de um ou mais conteúdos escolares. A tese central é que os materiais e recursos utilizados estejam voltados a uma aprendizagem significativa na perspectiva de David Ausubel.

Ao elencar as condições para que ocorra uma aprendizagem significativa da forma que preconiza Ausubel, Moreira (2011) informa que o material a ser aprendido deve ser potencialmente significativo para o aprendiz.

Para cumprir essa necessidade, Moreira (2011) propõe a construção de sequências didáticas que ele nomeia: Unidades de Ensino Potencialmente Significativas. Para tanto propõe oito passos, que ele nomeia de Aspectos Sequenciais:

1. definir o tópico específico a ser abordado, identificando seus aspectos declarativos e procedimentais tais como aceitos no contexto da matéria de ensino na qual se insere esse tópico;

2. criar/propor situação(ções) discussão, questionário, mapa conceitual, mapa mental, situação-problema, etc. que leve(m) o aluno a externalizar seu conhecimento prévio, aceito ou não-aceito no contexto da matéria de ensino, supostamente relevante para a aprendizagem significativa do tópico (objetivo) em pauta;

3. propor situações-problema, em nível bem introdutório, levando em conta o conhecimento prévio do aluno, que preparem o terreno para a introdução do conhecimento (declarativo ou procedimental) que se pretende ensinar; estas situações-problema podem envolver, desde já, o tópico em pauta, mas não para começar a ensiná-lo; tais situações-problema podem funcionar como organizador prévio; são as situações que dão sentido aos novos conhecimentos, mas, para isso, o aluno deve percebê-las como problemas e deve ser capaz de modelá-las mentalmente; modelos mentais são funcionais para o aprendiz e resultam da percepção e de conhecimentos prévios (invariantes operatórios); estas situações-problema iniciais podem ser propostas através de simulações computacionais, demonstrações, vídeos, problemas do cotidiano, representações veiculadas pela mídia, problemas clássicos da matéria 
de ensino, etc., mas sempre de modo acessível e problemático, i.e., não como exercício de aplicação rotineira de algum algoritmo;

4. uma vez trabalhadas as situações iniciais, apresentar o conhecimento a ser ensinado/aprendido, levando em conta a diferenciação progressiva, i.e., começando com aspectos mais gerais, inclusivos, dando uma visão inicial do todo, do que é mais importante na unidade de ensino, mas logo exemplificando, abordando aspectos específicos; a estratégia de ensino pode ser, por exemplo, uma breve exposição oral seguida de atividade colaborativa em pequenos grupos que, por sua vez, deve ser seguida de atividade de apresentação ou discussão em grande grupo;

5. em continuidade, retomar os aspectos mais gerais, estruturantes (i.e., aquilo que efetivamente se pretende ensinar), do conteúdo da unidade de ensino, em nova apresentação (que pode ser através de outra breve exposição oral, de um recurso computacional, de um texto, etc.), porém em nível mais alto de complexidade em relação à primeira apresentação; as situaçõesproblema devem ser propostas em níveis crescentes de complexidade; dar novos exemplos, destacar semelhanças e diferenças relativamente às situações e exemplos já trabalhados, ou seja, promover a reconciliação integradora; após esta segunda apresentação, propor alguma outra atividade colaborativa que leve os alunos a interagir socialmente, negociando significados, tendo o professor como mediador; esta atividade pode ser a resolução de problemas, a construção de uma mapa conceitual ou um diagrama $V$, um experimento de laboratório, um pequeno projeto, etc., mas deve, necessariamente, envolver negociação de significados e mediação docente;

6. concluindo a unidade, dar seguimento ao processo de diferenciação progressiva retomando as características mais relevantes do conteúdo em questão, porém de uma perspectiva integradora, ou seja, buscando a reconciliação integrativa; isso deve ser feito através de nova apresentação dos significados que pode ser, outra vez, uma breve exposição oral, a leitura de um texto, o uso de um recurso computacional, um áudio-visual, etc.; o importante não é a estratégia, em si, mas o modo de trabalhar o conteúdo da unidade; após esta terceira apresentação, novas situações-problema devem ser propostas e trabalhadas em níveis mais altos de complexidade em relação às situações anteriores; essas situações devem ser resolvidas em atividades colaborativas e depois apresentadas e/ou discutidas em grande grupo, sempre com a mediação do docente;

7. a avaliação da aprendizagem através da UEPS deve ser feita ao longo de sua implementação, registrando tudo que possa ser considerado evidência de aprendizagem significativa do conteúdo trabalhado; além disso, deve haver uma avaliação somativa individual após o sexto passo, na qual deverão ser propostas questões/situações que impliquem compreensão, que evidenciem captação de significados e, idealmente, alguma capacidade de transferência; tais questões/situações deverão ser previamente validadas por professores experientes na matéria de ensino; a avaliação do desempenho do aluno na UEPS deverá estar baseada, em pé de igualdade, tanto na avaliação formativa (situações, tarefas resolvidas colaborativamente, registros do professor) como 
na avaliação somativa;

8. a UEPS somente será considerada exitosa se a avaliação do desempenho dos alunos fornecer evidências de aprendizagem significativa (captação de significados, compreensão, capacidade de explicar, de aplicar o conhecimento para resolver situações-problema). A aprendizagem significativa é progressiva, o domínio de um campo conceitual é progressivo; por isso, a ênfase em evidências, não em comportamentos finais.

(MOREIRA, 2011, p. 5)

Para finalizar, Moreira (2011) apresenta ainda alguns aspectos transversais:

- em todos os passos, os materiais e as estratégias de ensino devem ser diversificados, o questionamento deve ser privilegiado em relação às respostas prontas e o diálogo e a crítica devem ser estimulados;

- como tarefa de aprendizagem, em atividades desenvolvidas ao longo da UEPS, pode-se pedir aos alunos que proponham, eles mesmos, situações-problema relativas ao tópico em questão;

- embora a UEPS deva privilegiar as atividades colaborativas, a mesma pode também prever momentos de atividades individuais.

(MOREIRA, 2011, p. 5)

Quanto ao material potencialmente significativo, Moreira (2011, p. 10) destaca ainda que o significado está nas pessoas, não nas coisas. Sendo assim, não existem livros ou aulas significativas, no entanto, estes podem tornar-se significativos quando apresentam um significado lógico ter estrutura, organização, exemplos, linguagem adequada, enfim, serem aprendíveis, somando a isso os conhecimentos prévios adequados para relacionar-se com os conhecimentos apresentados por esses materiais.

Os passos apresentados por Moreira (2011), não necessitam serem seguidos de forma tão rígida, mas devem fundamentalmente oportunizar a incorporação de novas situações problemas, proporcionando que o professor faça suas adequações, para que possam ser utilizados como forma de subsidiar a abordagem de temas no ensino das ciências da natureza.

\section{Metodologia}

\section{A metodologia de pesquisa}

Há um clamor pela necessidade de atualização curricular do ensino de Física, em especial pela introdução de tópicos de Física Moderna e Contemporânea, assim como preconiza os PCN+. No entanto, o que se tem visto são ações que visam explicar o porquê e se é possível ensinar FMC no Ensino Médio, enquanto que, quanto ao como fazer poucas ações efetivas são apresentadas (SIQUEIRA, 2006). Nesse sentido, é apresentado uma proposta de passo a passo do como fazer para se ensinar tópicos de FMC no Ensino Médio. 
Para a realização deste trabalho optou-se por uma metodologia fundamentada no levantamento de conhecimentos prévios, a confecção e uso de materiais potencialmente significativos, e por fim, uma busca por evidências da presença de aprendizagem significativa. Assim, elaborou-se uma sequência didática sobre Física de Partículas que introduz os principais conceitos dessa área que se acredita estar ao alcance dos alunos.

A sequência didática inicia-se com a aplicação de um questionário inicial com o intuito de identificar conhecimentos prévios. A partir daí, inicia-se um série de explanações sobre conceitos relativos à Física de Partículas. Quando se percebe que houve assimilação, e por consequência mudança na estrutura cognitiva, são apresentados novos conceitos com maior grau de complexidade. Esse processo é incrementado com a execução de jogos de cartas, onde os alunos devem demonstrar os conhecimentos adquiridos sobre as partículas elementares. A sequência didática encerra-se com a aplicação de um questionário final e de uma pesquisa de opinião.

\section{I.1 Contextualização}

Aplicou-se a sequência didática entre os meses de abril e maio de 2018, em uma Escola Estadual, localizada na cidade de Unaí-Mg. A escola oferece o Ensino Médio em tempo integral, o Ensino Médio na modalidade EJA no noturno, e oferece ainda cursos técnicos em: Informática, Administração, Recursos Humanos e Marketing, também no noturno.

Desenvolveu-se o trabalho com três turmas da terceira série do Ensino Médio (turno vespertino). Cada turma conta com um número de cerca de trinta e dois alunos matriculados, sendo que do total, no máximo cinco são infrequentes.

O público da escola é composto em sua maioria por alunos de baixa renda, oriundos da zona rural, que por questão de logística, são alocados nessa escola devido à sua localização central.

\section{I.2 Atividades desenvolvidas}

Para a realização da pesquisa, optou-se por seguir as orientações de Moreira (2011) para a estruturação e desenvolvimento de uma UEPS. Desenvolveu-se a sequência didática durante oito encontros, sendo que cada encontro se compôs por duas aulas geminadas de cinquenta minutos cada. Durante os primeiros encontros, buscou-se a identificação de conceitos subsunçores por meio da análise dos mapas conceituais preliminares, com o objetivo de ancorar os novos conceitos relevantes da estrutura de conhecimento dos alunos.

Durante o desenvolvimento da sequência didática, o pesquisador manteve-se atento à participação dos estudantes durante todo o processo, oferecendo condições para que se motivassem. Realizou-se ainda uma análise dos mapas conceituais desenvolvidos ao final dos encontros, bem como uma análise das respostas apresentadas pelos estudantes aos questionários impressos, com o intuito de identificar evidências de aprendizagem significativa. 


\section{I.3 Etapas da sequência didática}

Para uma melhor organização, a construção e aplicação da Unidade de Ensino Potencialmente Significativa - UEPS estruturou-se de forma que ocorresse em oito etapas, a saber:

\section{Etapa 1 - Situação inicial}

Apresentação da proposta de trabalho, aplicação de um questionário de verificação inicial, definição e construção de mapas conceituais sobre temas pré-determinados.

Nesse momento, os estudantes foram informados sobre a pesquisa desenvolvida no âmbito do Mestrado em Ensino de Física ao qual o professor é aluno e que esta se tratava de um trabalho sobre Partículas Elementares e Interações Fundamentais. Nesse momento já surgiram algumas dúvidas a respeito dos temas tratados e que até então eram totalmente novos para alguns deles.

Após uma breve explanação sobre o tema, convidaram-se os alunos a participarem da pesquisa e após terem aceitado, iniciou-se uma explanação sobre como esta ocorreria e as etapas a serem desenvolvidas.

Neste encontro os alunos responderam a um questionário de verificação inicial que se encontra no apêndice A, com o intuito de identificar subsunçores. Logo após, os alunos realizaram a construção de um mapa conceitual. A elaboração do mapa conceitual seguiu as etapas:

- Apresentação de slides sobre o que é, e como construir mapas conceituais (apêndice B).

- Elaboração de um mapa conceitual pelo professor, a título de exemplo. O tema escolhido foi a Eletricidade. Os alunos ditaram conceitos relacionados à Eletricidade, enquanto o professor os anotava no quadro. Assim que vários tópicos foram levantados, estes foram organizados no mapa conceitual.

- Solicitação de construção em grupos de um mapa conceitual, com os temas: ramos da física, da química e da biologia.

Ao final do encontro, onde os alunos foram informados sobre o projeto a ser desenvolvido, identificou-se possíveis subsunçores e houve uma familiarização com os mapas conceituais, solicitou-se aos alunos que realizassem uma pesquisa sobre o que foi o Big Bang, para chamar a atenção dos estudantes para o conteúdo que seria abordado no próximo encontro.

\section{Etapa 2 Situação-problema 1}

O que foi o Big Bang? Realizou-se uma discussão sobre o que foi o Big Bang, a formação do universo, a formação das primeiras partículas elementares, dos primeiros elementos da tabela periódica e das primeiras estrelas.

A aula iniciou-se com um debate sobre a pesquisa realizada pelos estudantes sobre o tema determinado na aula anterior. Para tanto, discutiu-se em sala de aula o resultado da investigação sobre o que foi o Big Bang e a formação do universo. Para um melhor aproveitamento do debate, sempre que necessário realizava-se intervenções por parte do investigador. 
Durante o debate evidenciou-se que grande parte dos alunos não realizou a pesquisa solicitada, demonstrando pouco envolvimento destes com o trabalho. Apesar disso, a discussão teve um bom andamento, uma vez que, conseguiu-se atingir o objetivo desejado.

Após a discussão inicial, procedeu-se a apresentação de dois vídeos disponíveis no Youtub. O primeiro mais geral, tratando sobre o Big Bang, e o segundo, sobre a formação das primeiras partículas. Os vídeos escolhidos tratavam dos seguintes temas:

- O Big Bang;

- A origem do universo;

- Expansão do universo;

- Formação das primeiras partículas elementares;

- Formação dos primeiros elementos da tabela periódica;

- Formação das primeiras estrelas.

Para completar a apresentação dos slides, demonstrou-se um infográfico com a expansão temporal do universo, onde os alunos puderam entender melhor como o universo evoluiu nos primeiros instantes. Nesse momento, recomendou-se aos alunos que gostariam de aprofundar seus conhecimentos nesse assunto, que realizassem uma leitura do livro: $\mathrm{O}$ discreto charme das partículas elementares, da autora Maria Cristina Batoni Abdalla.

Por fim, com o intuito de verificar indícios de aprendizagem significativa, solicitou-se aos estudantes que construíssem mapas conceituais representando o Big Bang e a formação das primeiras partículas elementares, dos primeiros elementos da tabela periódica e a formação das primeiras estrelas.

\section{Etapa 3 Situação-problema 1I}

Nova situação-problema, em nível mais alto de complexidade: apresentar e explicar, o que são os aceleradores de partículas e sua importância para o estudo do universo.

Nesta aula discutiu-se o que é um acelerador de partículas, como é o seu funcionamento, quais são as pesquisas desenvolvidas, qual é o seu objetivo e quais são os principais aceleradores em funcionamento distribuídos pelo mundo.

A aula iniciou-se com a exibição de um vídeo disponível no Youtube . O vídeo fala sobre o acelerador de partículas da Organização Europeia para a Pesquisa Nuclear, conhecido como (CERN), acrônimo para Conseil Européen pour la Recherche Nucléaire. O vídeo trata dos seguintes temas:

- Definição de (CERN);

- Principais pesquisas desenvolvidas;

- O objetivo das pesquisas desenvolvidas;

- Funcionamento de um acelerador;

- Descobertas realizadas até aqui; 
- Principais desafios e expectativas para o futuro;

Por fim, utilizou-se uma apresentação disponível na página do Prezi , com o intuito de aprofundar o assunto sobre acelerador de partículas. A apresentação trata dos seguintes temas:

- Funcionamento dos aceleradores;

- Tipos de aceleradores;

- Principais aceleradores espalhados pelo mundo;

- Aceleradores brasileiros.

Nesse instante, discutiram-se questões que até então, para os alunos não passavam de ficção científica. Tais temas foram: matéria e antimatéria; buracos negros e o fim do mundo; a expansão do universo; dentre outros.

\section{Etapa 4 Situação-problema 1II}

Nova situação-problema, em nível mais alto de complexidade: apresentar e explicar, o que é o modelo padrão, a família das partículas elementares e sobre as interações fundamentais.

Nessa aula discutiu-se assuntos relacionados às partículas elementares e interações fundamentais e sobre temas como: massa, carga elétrica e spin das partículas.

A aula iniciou-se com a apresentação de um vídeo disponível no Youtube , com o objetivo de promover uma discussão sobre as partículas elementares. O vídeo aborda o modelo padrão, as partículas elementares, as interações fundamentais e discute brevemente sobre os hádrons.

- Modelo padrão;

- Partículas elementares;

- Interações fundamentais;

- Bóson de Higgs.

Em um segundo momento, utilizou-se um texto de (OSTERMANN e CAVALCANTI, 2001) para aprofundar a discussão sobre Física de Partículas e Interações Fundamentais. O texto encontra-se na Revista Física na Escola, v. 2, n. 1, 2001, e aborda os seguintes temas:

- Partículas fundamentais existentes no universo;

- Modelo padrão;

- Interações fundamentais;

- Massas de repouso, cargas elétricas e spin.

Em um terceiro momento, apresentou-se aos alunos um texto elaborado por (MOREIRA, 2004) onde ele apresenta um mapa conceitual sobre Partículas e Interações. O texto onde o mapa conceitual é apresentado encontra-se na Revista Física na Escola, v. 5, n. 2, 2004, e aborda os seguintes temas. 
- Partículas elementares e interações fundamentais;

- Mapa conceitual para partículas elementares;

- Mapa conceitual para interações fundamentais.

Por fim, solicitou-se aos alunos que em grupo, construíssem um mapa conceitual abordando o tema: Partículas Elementares e Interações Fundamentais.

Etapa 5 Execução do primeiro jogo de cartas (Dança dos Quarks e Léptons)

Aplicação de um jogo de cartas sobre as interações fundamentais, família das partículas e modelo padrão, com o objetivo de consolidar os conceitos apresentados.

Deu-se início a aula com a divisão de grupos, com três ou quatro estudantes para utilizarem o jogo de cartas.

O baralho é composto por cartas:

- léptons;

- antiléptons;

- quarks;

- antiquarks;

- bósons

O jogo apresenta trinta e seis cartas, sendo que, de acordo com o número de alunos participantes em cada rodada é possível associar dois ou mais baralhos.

As regras do jogo são:

- cada aluno deverá receber oito cartas em cada rodada;

- o primeiro a jogar é o aluno que se encontra após o que distribuiu as cartas;

- na próxima rodada baralha o aluno que começou o jogo na rodada anterior;

- o aluno que receber as cartas primeiro, é o primeiro a pegar uma carta no monte e descartar aquela que não lhe serve;

- o próximo aluno pode pegar a carta descartada ou pegar uma no monte;

- cada aluno deverá formar duplas partícula/antipartícula, respeitando a família das cartas, ex: elétron/antielétron;

- ganha a rodada o aluno que formar quatro duplas primeiro;

- cada rodada vale um ponto;

- ganha o jogo o aluno que somar três pontos primeiro. 
O jogo objetivou familiarizar o aluno com as famílias das partículas elementares para em seguida, através de outros jogos, aprofundar ainda mais sobre as leis de conservação e formação de outras partículas.

\section{Etapa 6 Situação-problema 1V}

As partículas são compostas do que? Promover uma explanação e discussão sobre os quarks, composição dos hádrons e leis de conservação.

Realizou-se uma discussão sobre os quarks, a forma como se agrupam para formarem os hádrons, as leis de conservação que regem sua formação e as diferenças básicas entre hádrons e léptons e entre mésons e bárions.

Deu-se início a aula com uma apresentação de slides sobre a definição e formação dos hádrons. (ver apêndice $\mathrm{C}$ ).

- diferenças entre hádrons e léptons;

- diferenças entre mésons e bárions;

- quarks;

- sabores dos quarks;

- cores dos quarks;

- combinação de quarks;

- carga elétrica;

- spin.

Logo em seguida, apresentou-se um vídeo disponível no Youtube, onde se discutiu sobre o que são os quarks e aborda os temas:

- quarks;

- formação de hádrons;

- mésons e bárions;

- conservação da carga elétrica;

Em seguida exibiu-se mais um vídeo que aborda mais especificamente as características do quark up.

\section{Etapa 7 Execução do segundo jogo de cartas (Dança dos Quarks e Léptons)}

Aplicação do segundo jogo de cartas sobre o a constituição dos hádrons, obedecendo a conservação da carga elétrica.

A aula objetivou a retomada de discussão sobre as partículas elementares e a consolidação dos conceitos apresentados sobre a constituição dos hádrons, sobre os quarks e a conservação da carga elétrica.

Deu-se início a aula com a divisão de grupos de três ou quatro estudantes para utilizarem o jogo de cartas.

O jogo é composto por: 
- trinta e seis cartas quarks;

- dado de partículas mésons;

- dado de partículas bárions;

As regras do jogo são:

- os alunos podem jogar individualmente ou formando duplas;

- o professor arremessa um dado de cada vez, podendo ser o dado méson ou bárion;

- o jogador deve formar a partícula sorteada respeitando a conservação da carga elétrica;

- o jogador pode consultar a tabela com os componentes quarks de cada partícula;

- cada aluno deverá receber nove cartas em cada rodada;

- o primeiro a jogar é o aluno que se encontra após o que distribuiu as cartas;

- na próxima rodada, baralha o aluno que começou o jogo na rodada anterior;

- o aluno que receber as nove cartas primeiro, é o primeiro a pegar uma carta no monte e descartar aquela que não lhe serve;

- o próximo aluno pode pegar a carta descartada ou pegar uma no monte;

- ganha a rodada o aluno que primeiro formar a partícula sorteada no dado;

- cada rodada vale um ponto;

- ganha o aluno ou dupla que somar três pontos primeiro.

A critério do professor, novas regras e formas de jogar podem ser criadas, uma vez que o jogo é muito versátil.

\section{Etapa 8 - Avaliação Sondagem Final}

No oitavo encontro, aplicou-se um questionário de verificação final onde se comparou as respostas obtidas, com as respostas do questionário de verificação inicial. O intuito da comparação é o de verificar se houve indícios de aprendizagem significativa. (veja apêndice D).

\section{Etapa 9 Avaliação da própria UEPS}

Para finalizar a UEPS, aplicou-se ainda uma pesquisa de opinião com o intuito de identificar possíveis falhas e se possível, propor melhorias. A pesquisa objetivou ainda, medir o nível de satisfação dos alunos com a realização da pesquisa. (veja apêndice E). 

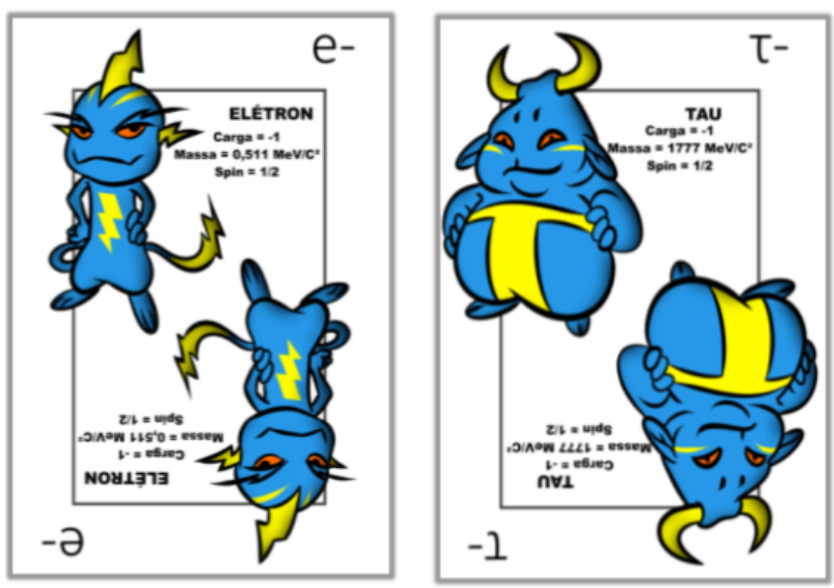

Figura 1: Exemplo de cartas léptons. Fonte: Elaborado pelos autores.

\section{O jogo Dança dos Quarks e Léptons}

Como várias escolas públicas não possuem laboratórios ou recursos para aquisição de equipamentos, pensou-se em uma forma para promover a transposição didática sobre a Física de Partículas para alunos da terceira série do Ensino Médio. Após analisar a produção bibliográfica existente, optou-se por desenvolver e aplicar um jogo de cartas sobre as Partículas Elementares e as Interações Fundamentais, como alternativa para a falta de laboratórios.

A proposta do jogo consiste em utilizar um conjunto de cartas com as principais características de algumas partículas fundamentais, onde o intuito é resolver problemas propostos em sala de aula. As jogadas devem ocorrer de acordo com as regras do Modelo Padrão e das Leis de Conservação. Dessa forma, os alunos terão a oportunidade de aprender sobre a composição da matéria e as interações fundamentais de forma lúdica.

\section{II.1 As cartas léptons}

No jogo existem 6 cartas léptons (o múon; o elétron; o tau), seus respectivos neutrinos, duas cartas curingas e seus respectivos antiléptons, conforme a figura 1.

Léptons são partículas leves em termos de massa, não possuem estrutura interna e podem ou não possuir carga e, junto com os quarks, são os elementos básicos que constituem a matéria.

Tanto os quarks quanto os léptons obedecem ao princípio de exclusão de Pauli, que basicamente diz que é impossível existir duas partículas com um mesmo estado quântico. Por exemplo, se dois elétrons possuem os números quânticos $n, \ell, m_{\ell}$ iguais, então o número de spin $m_{S}$ será diferente. Dessa forma os léptons e os quarks são classificados como férmions.

\section{II.2 Cartas de antipartículas dos léptons}

Para cada férmion existente no Modelo Padrão existe uma partícula correspondente, bastante similar, com as mesmas propriedades, exceto a carga, que é oposta. Esta partícula 


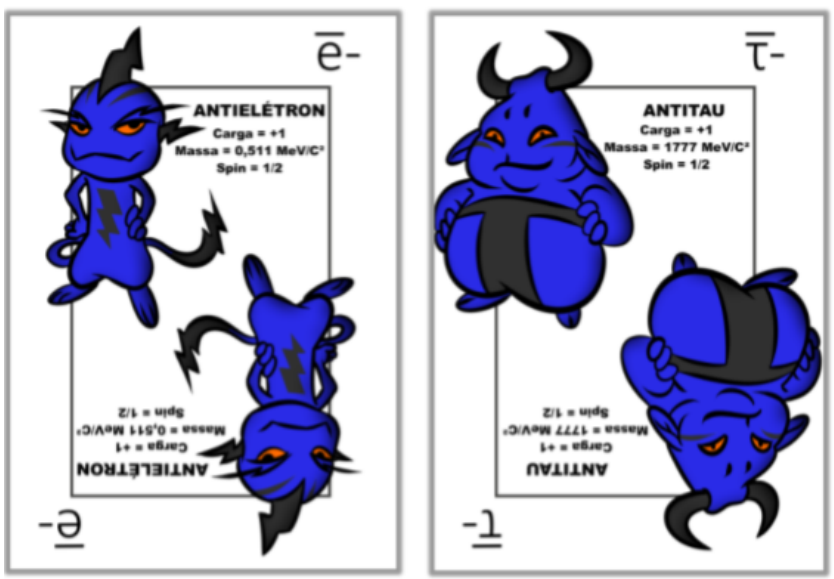

Figura 2: Exemplos de cartas antiléptons. Fonte: Elaborado pelos autores.

correspondente é chamada de antipartícula. As antipartículas dos léptons podem ser escritas adicionando o sinal da carga sobrescrita à letra que o representa, conforme exemplos na figura 2.

O pósitron, antipartícula do elétron, pode ser escrito como $e^{+}$. O neutrino não tem carga elétrica, tem um sabor, então o antineutrino possui um sabor oposto.

Sabor e cor são palavras usadas na Física que não possuem o significado de uso comum, são usados para indicar um tipo de carga que não é de origem elétrica.

\section{II.3 As cartas quarks}

Quarks são partículas que possuem cor e sabor, seus correspondentes antiquarks possuem cores e sabores opostos. Essas partículas estão confinadas, interagindo entre si.

Não é possível observá-los de forma isolada, mas sim em combinações. Tais combinações podem resultar em outras partículas chamadas de hádrons que podem ser fermiônicos, compostos por três quarks (bárions), bosônicos ou mesônicos (compostos por um par de quark e antiquark). Na natureza são observados os prótons e nêutrons. Segue exemplo das cartas quarks na figura 3.
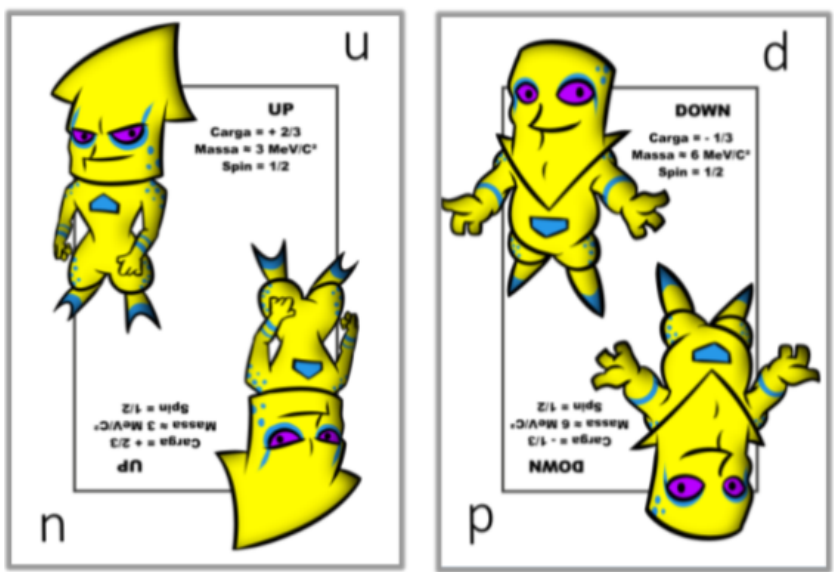

Figura 3: Exemplos de cartas quarks. Fonte: Elaborado pelos autores. 
O jogo é composto por 6 cartas quarks (top, up, bottom, down, strange e charm), seus respectivos antiquarks e dois curingas.

\section{II.4 As cartas antiquarks}

Antiquark são as antipartículas dos quarks. Como cada quark tem o seu próprio antiquark, logo existem seis antiquarks que são: (antiquark up; antiquark down; antiquark charm; antiquark strange; antiquark botton; antiquark top), segue exemplo das cartas antiquarks na figura 4.
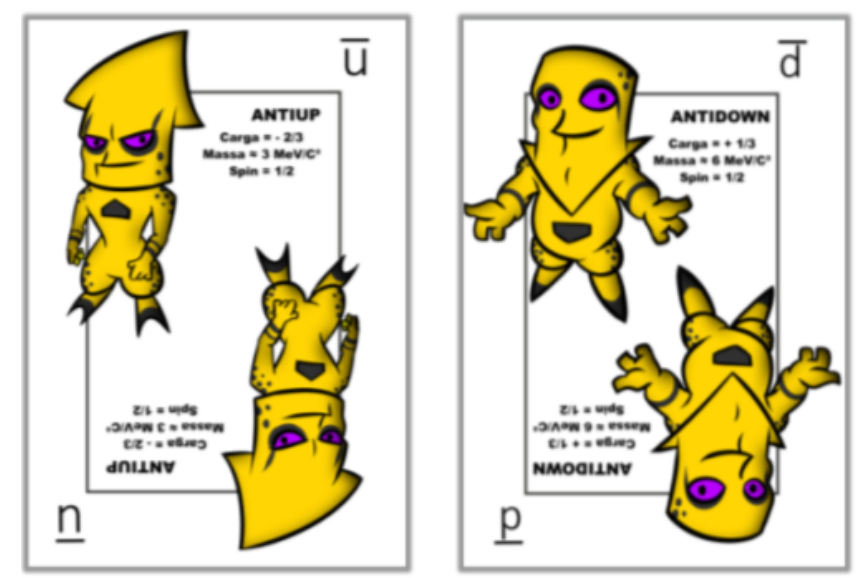

Figura 4: Cartas antiquarks. Fonte: Elaborado pelos autores.

\section{II.5 As cartas bósons}

O jogo é composto por seis cartas bósons: o fóton, o glúon, os bósons $\mathrm{W}$ e $\mathrm{Z}$ e o Bóson de Higgs, conforme exemplos na figura 5.
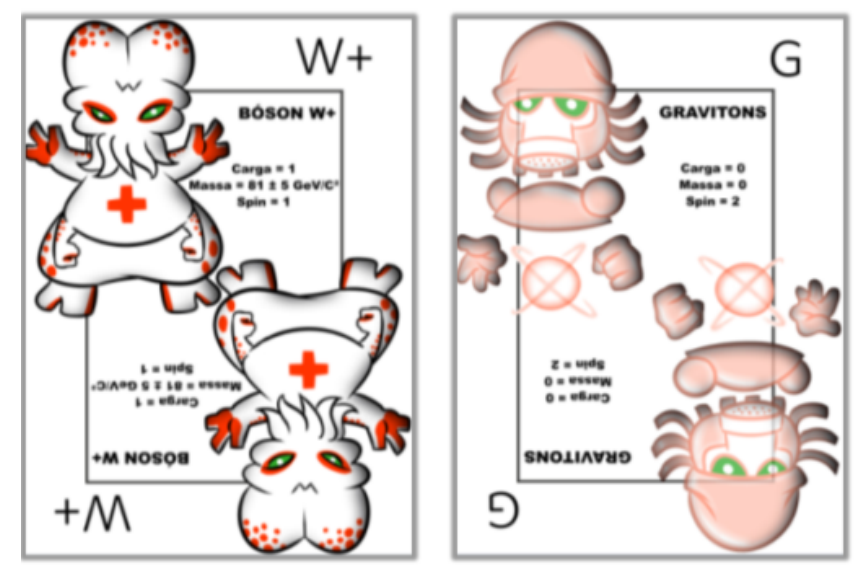

Figura 5: Exemplo de cartas bósons. Fonte: Elaborado pelos autores.

A maior diferença entre bósons e férmions é que os bósons não obedecem ao princípio de exclusão de Pauli. Bósons são conhecidos como partículas de calibre, responsáveis pelas interações fundamentais. 


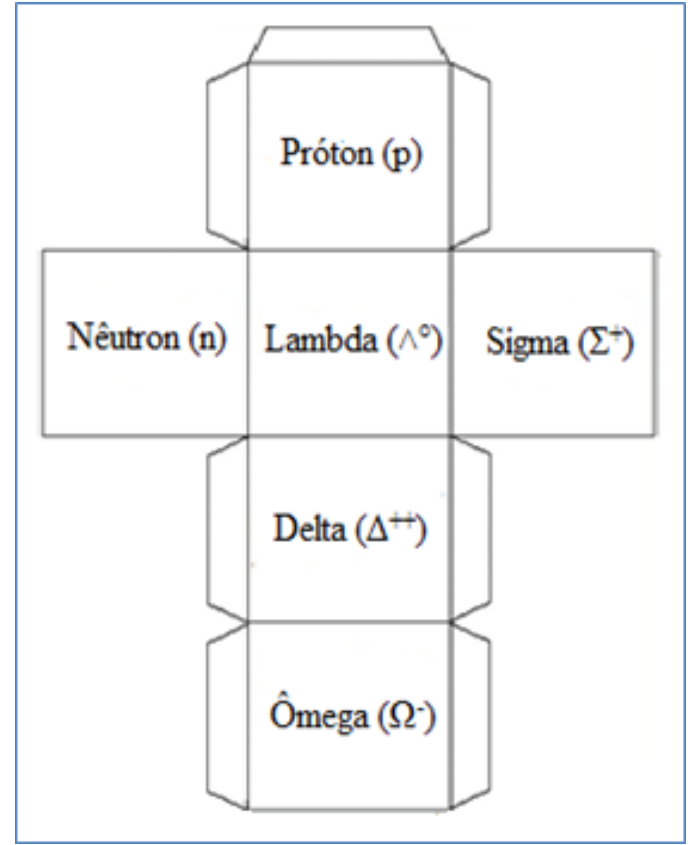

Figura 6: Dado de bárions. Fonte: Elaborado pelos autores

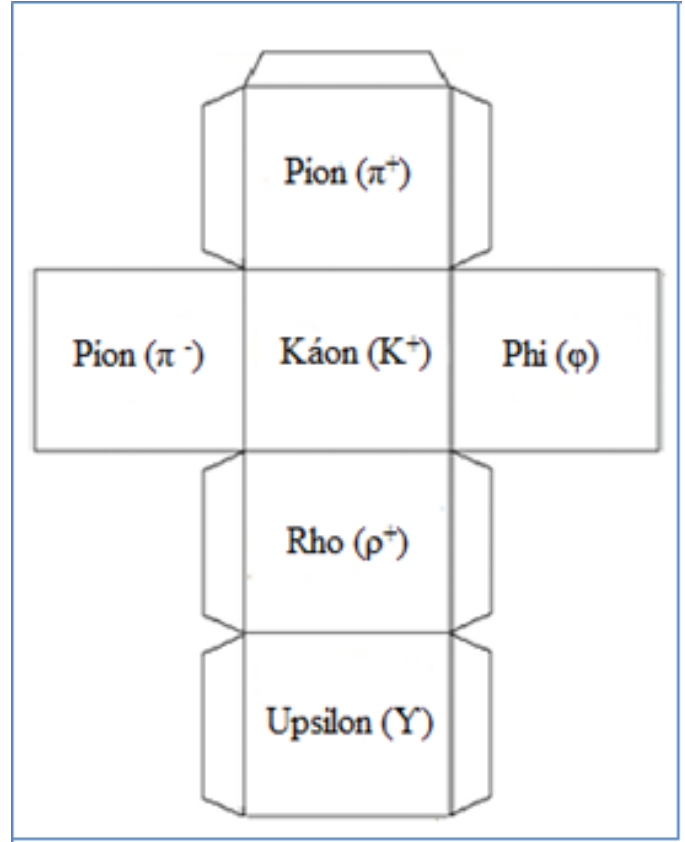

Figura 7: Dado de mésons. Fonte: Elaborado pelos autores

\section{II.6 Dado das partículas hádrons}

Um hádron é um composto de partículas subatômicas regido pela interação forte. Bárions são compostos de três quarks e têm spin semi-inteiro, ou seja, obedecem ao princípio de exclusão de Pauli, caracterizando-se como férmions. Exemplos: próton, nêutron e lambda. Os bárions são partículas em cuja composição existe três quarks . A antipartícula dos bárions são os antibárions, cuja composição existem três antiquarks .

O primeiro dado construído para sortear a partícula que o aluno deveria criar, foi o dado de bárions, conforme a figura 6.

Para auxiliar o aluno no momento de criar a partícula sorteada pelo dado, criou-se a tabela de bárions e antibárions, conforme a tabela 1.

Tabela 1: Bárions e Antibárions. Fonte: Elaborado pelos autores.

\begin{tabular}{|c|c|c|c|c|c|}
\hline \multicolumn{7}{|c|}{ Férmions-Hádrons-Bárions-Antibárions } \\
\hline Símbolo & Nome & Quarks & Carga Elétrica & Massa $\left(G e v / c^{2}\right)$ & Spin \\
\hline$p$ & próton & uud & 1 & 0,938 & $1 / 2$ \\
\hline $\bar{p}$ & antipróton & $\bar{u} \bar{u} d$ & -1 & 0,938 & $1 / 2$ \\
\hline$n$ & neutron & uud & 0 & 0,940 & $1 / 2$ \\
\hline$\Lambda_{-}^{0}$ & lambda & $u d s$ & 0 & 1,116 & $1 / 2$ \\
\hline$\Omega^{-1}$ & omega & $s s s$ & -1 & 1,672 & $3 / 2$ \\
\hline
\end{tabular}

Mésons são compostos de um quark e outro antiquark e são bósons, ou seja, têm spin inteiro. Os mésons são partículas subatômicas compostas por um par de quark-antiquark $(q \bar{q})$ geradas por colisões entre partículas que possuem altas energias. Por exemplo, o píon é um méson composto por um quark e um antiquark. 
O segundo dado a ser utilizado no jogo é o dado de mésons, conforme a figura 7. Para auxiliar na construção dos mésons sorteados no dado, criou-se a tabela 2.

Tabela 2: Mésons. Fonte: Elaborado pelos autores.

\begin{tabular}{|c|c|c|c|c|c|}
\hline \multicolumn{7}{|c|}{ Hádrons-Bósons-Mésons } \\
\hline Símbolo & Nome & Quarks & Carga Elétrica & Massa $\left(G e v / c^{2}\right)$ & Spin \\
\hline$\pi^{+}$ & píon & $u \bar{d}$ & -1 & 0,140 & 0 \\
\hline$K^{-}$ & káon & $s \bar{u}$ & -1 & 0,494 & 0 \\
\hline$\rho^{+}$ & rho & $u \bar{d}$ & +1 & 0,770 & 1 \\
\hline$D$ & $D^{+}$ & $c \bar{d}$ & +1 & 1,869 & 0 \\
\hline$\eta_{c}$ & eta-c & $c \bar{c}$ & 0 & 2,979 & 0 \\
\hline
\end{tabular}

\section{II.7 Regra de combinação dos quarks}

Os quarks compõem os hádrons e podem se combinar em número de dois ou três para compor cada hádron. Essa associação de quarks obedece a algumas regras, dentre elas a da carga elétrica:

- A soma das cargas elétricas deve ser um número inteiro entre -2e e +2e. Ou seja, a carga final de um hádron deve ter um dos seguintes valores: $-2 \mathrm{e},-1 \mathrm{e}, 0,1 \mathrm{e}$ ou $2 \mathrm{e}$.

Os quarks possuem dois tipos de carga, a positiva e a negativa. Entretanto, eles possuem cargas semi-inteiras, isto é, uma fração da carga do elétron, antigamente considerada elementar. As cargas elétricas dos quarks são fracionárias e podem ser 2/3e e ou -1/3e.

\section{ANÁlise dE DADOS}

Para a análise dos resultados obtidos, consideraram-se as sondagens inicial e final, e, com o intuito de verificar o nível de satisfação dos alunos ao participarem da pesquisa, aplicou-se uma pesquisa de opinião em relação à sequência didática. As análises foram feitas buscando sempre indícios de Aprendizagem Significativa.

No que tange a aplicação da sequência didática, vale ressaltar que o projeto não foi baseado em uma simples aprendizagem mecânica de conceitos, contando puramente com recursos de memorização pela repetição literal e arbitrária de significados. Nesse sentido, buscou-se desenvolver as atividades partindo do pressuposto de promover uma Aprendizagem Significativa, apoiando-se nas situações problemas propostas e nos debates gerados.

Sempre que necessário recorreu-se aos conceitos e respectivos significados para o entendimento das atividades propostas. Por fim, destaca-se que a sondagem final ocorreu sem que os alunos fossem informados da data, com o intuito de evitar memorizações.

\section{Análise das sondagens inicial e final}

A primeira questão a ser analisada indagou se toda matéria comum é formada por quarks up, down e elétrons, conforme a figura 8. 


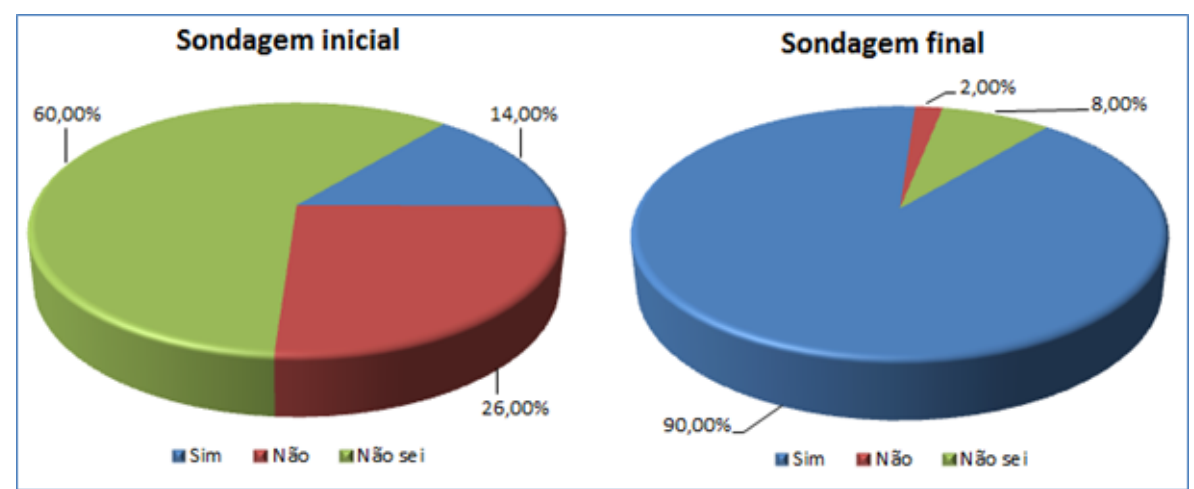

Figura 8: Toda matéria comum é formada por quarks up, down e elétrons. Fonte: Elaborado pelos autores.

Quanto à constituição da matéria, na sondagem inicial 60\% dos alunos afirmaram não saber a resposta e apenas 14\% marcaram a opção correta. Já na sondagem final, verificou-se que $90 \%$ marcaram a opção correta e o índice de erro foi de apenas $2 \%$. Mais uma vez, é possível considerar a presença de indícios de aprendizagem significativa.

Na segunda pergunta os alunos foram indagados se a antimatéria é ficção científica e não um fato científico. Os resultados obtidos encontram-se na figura 9.

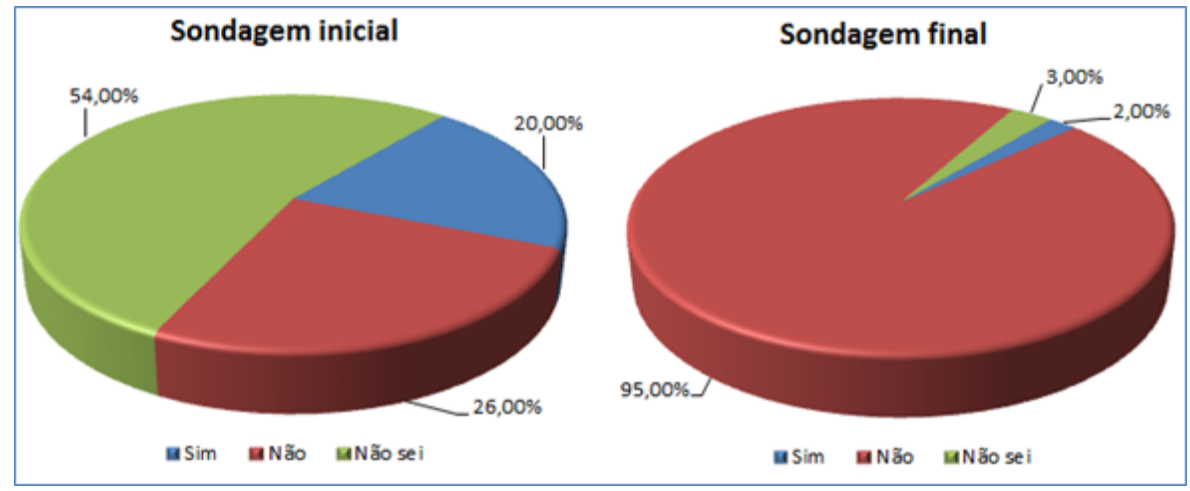

Figura 9: A antimatéria é ficção científica e não um fato científico. Fonte: Elaborado pelos autores.

Sobre a antimatéria ser ficção científica, na sondagem inicial 54\% dos alunos afirmaram não saber a resposta, e 20\% afirmaram que sim. Já na sondagem final, $95 \%$ dos alunos afirmaram que não. Esse dado revela que houve avanço significativo quanto a compreensão do que é a antimatéria.

Na terceira pergunta os alunos foram indagados se a força eletromagnética é responsável por gerar corrente elétrica. As respostas obtidas encontram-se na figura 10.

Quanto à força eletromagnética e corrente elétrica, na sondagem inicial $62 \%$ dos alunos afirmaram que há uma relação entre elas. Na sondagem final, esse índice aumentou ainda mais, uma vez que $85 \%$ marcaram a opção correta.

$\mathrm{Na}$ quarta pergunta os alunos foram indagados se o trabalho nos aceleradores de partículas nos ajuda a compreender o universo. As respostas encontram-se na figura 11.

Quanto aos aceleradores de partículas, na sondagem inicial ficou evidente que a maioria dos alunos não sabia o que é, e qual a sua finalidade, uma vez que 50\% dos alunos afirmaram 


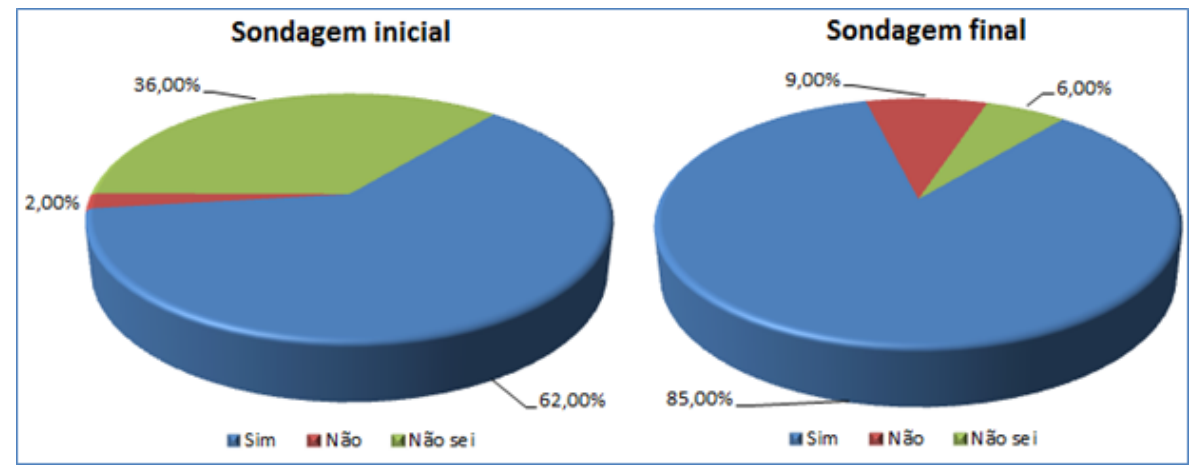

Figura 10: A força eletromagnética é responsável por gerar corrente elétrica. Fonte: Elaborado pelos autores.

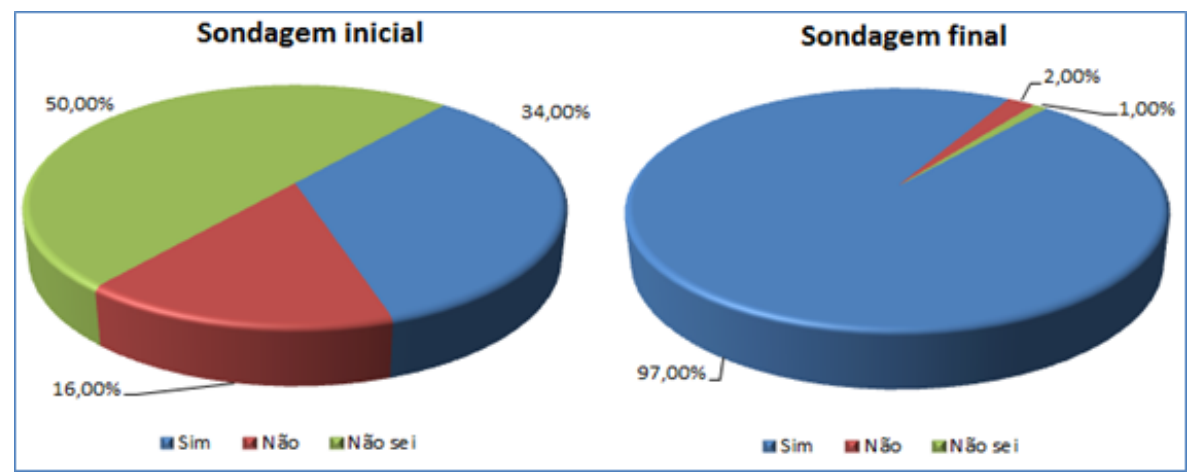

Figura 11: O trabalho feito nos aceleradores nos ajuda a compreender o universo. Fonte: Elaborado pelos autores.

não saber a resposta e 16\% marcaram a opção incorreta. Já na sondagem final 97\% dos alunos marcaram a opção correta.

Na quinta pergunta os alunos foram indagados se existe aceleradores de partículas no Brasil. As respostas obtidas encontram-se na figura 12.

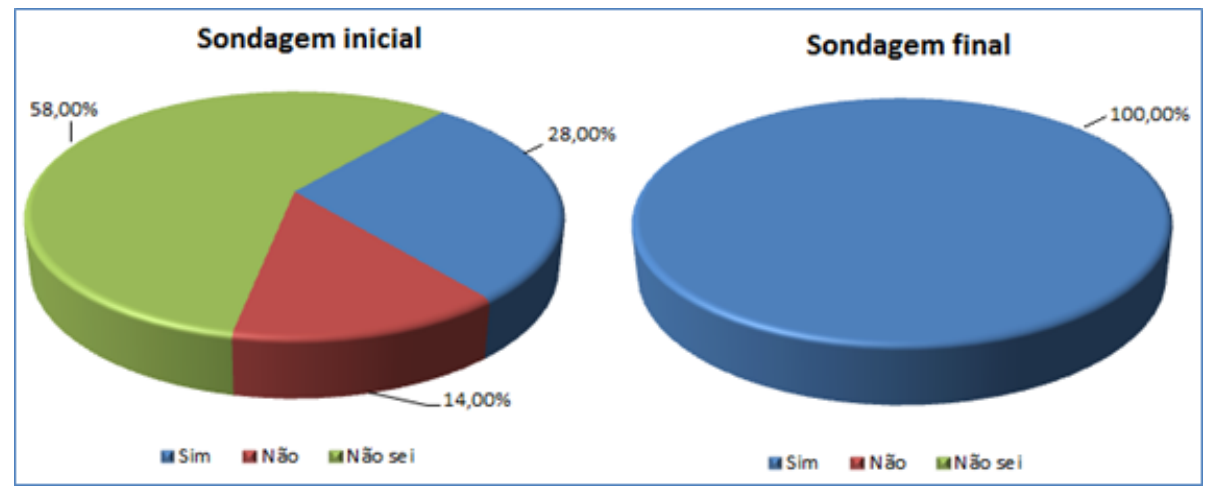

Figura 12: Existe aceleradores de partículas no Brasil. Fonte: Elaborado pelos autores.

Ao serem indagados na sondagem inicial sobre a presença de aceleradores de partículas no Brasil, 58\% dos alunos afirmaram não saber, 14\% afirmaram que não existe, e somente $28 \%$ afirmaram que no Brasil existem aceleradores.

Após a aplicação da sondagem final, percebeu-se que 100\% dos alunos compreenderam 
que no Brasil existem aceleradores de partículas e que em breve teremos um dos maiores do mundo.

Na sexta pergunta os alunos deveriam responder se o elétron é composto por partículas ainda menores. O consolidado das respostas obtidas para este item encontra-se na figura 13.

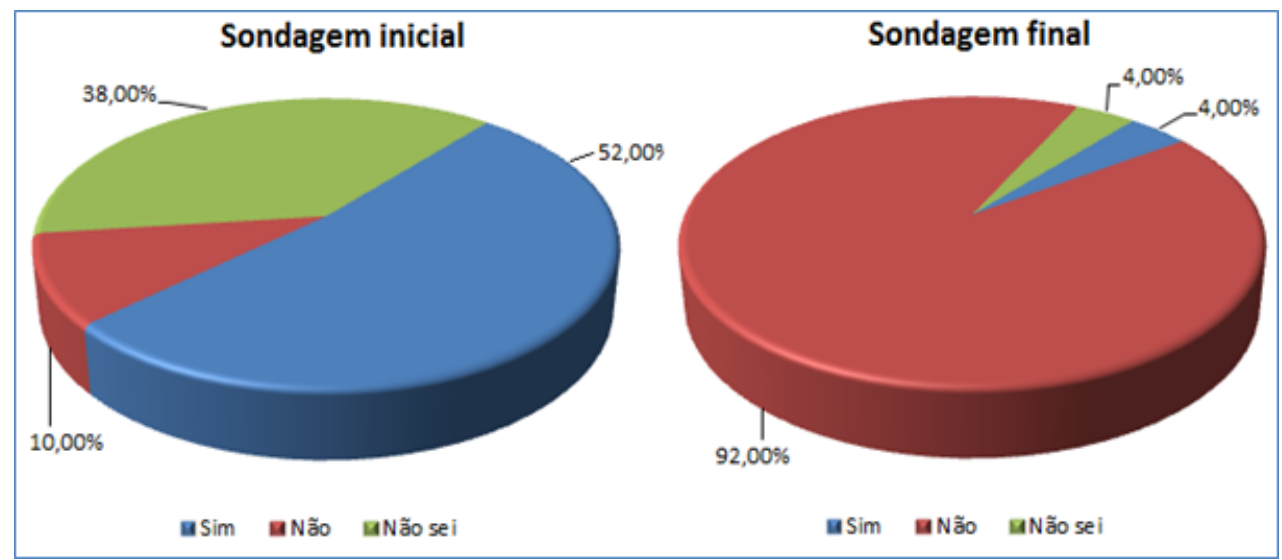

Figura 13: O elétron é composto por partículas ainda menores. Fonte: Elaborado pelos autores.

Na sondagem inicial, $52 \%$ dos alunos afirmaram que o elétron não é uma partícula fundamental, 38\% afirmaram não saber a resposta e somente 10\% marcaram a opção correta. Já após a aplicação da sondagem final, verifica-se que $92 \%$ dos alunos demonstraram ter compreendido que o elétron é indivisível, $4 \%$ afirmaram que sim, e somente $4 \%$ erraram a resposta.

Na sétima pergunta os alunos foram indagados se das forças fundamentais da natureza, a gravidade é a mais forte. O consolidado das respostas encontra-se na figura 14.

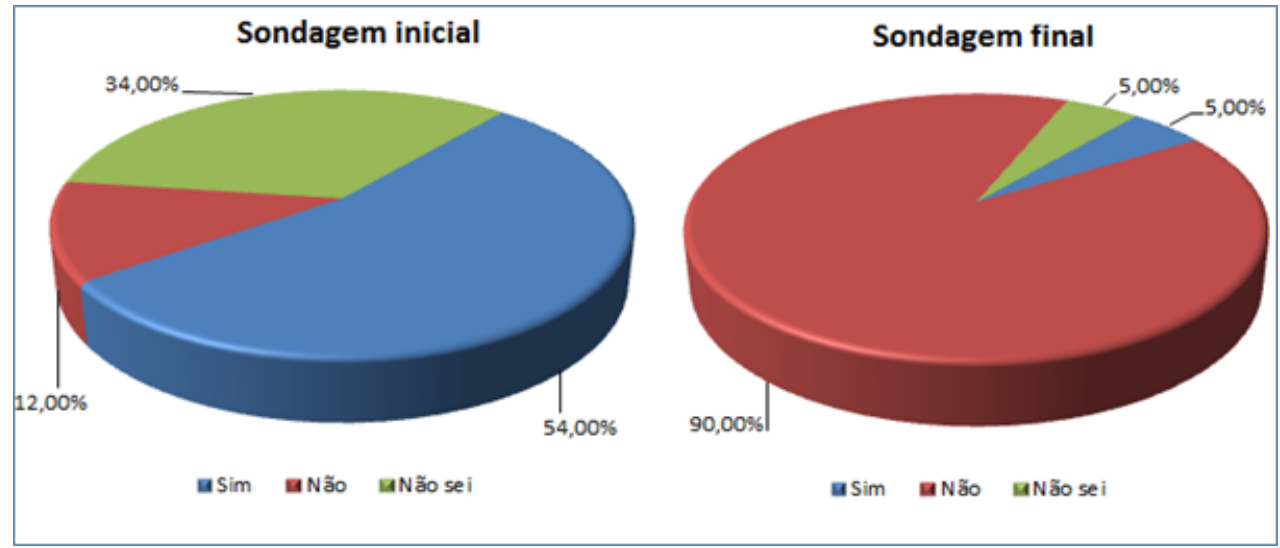

Figura 14: Das forças fundamentais da natureza, a gravidade é a mais forte. Fonte: Elaborado pelos autores.

Na sondagem inicial constatou-se que 54\% dos alunos afirmaram que a força da gravidade é a mais forte das quatro forças fundamentais da natureza e 34\% afirmaram não saber. Após a aplicação do projeto e ao analisar os dados da sondagem final, percebeu-se que $90 \%$ dos alunos afirmaram que a força da gravidade não é a mais forte, demonstrando uma evolução em relação aos conhecimentos sobre as quatro forças fundamentais da natureza. 
Na pergunta de número oito os alunos deveriam responder se toda a matéria é composta de léptons e quarks. As respostas obtidas encontram-se na figura 15.

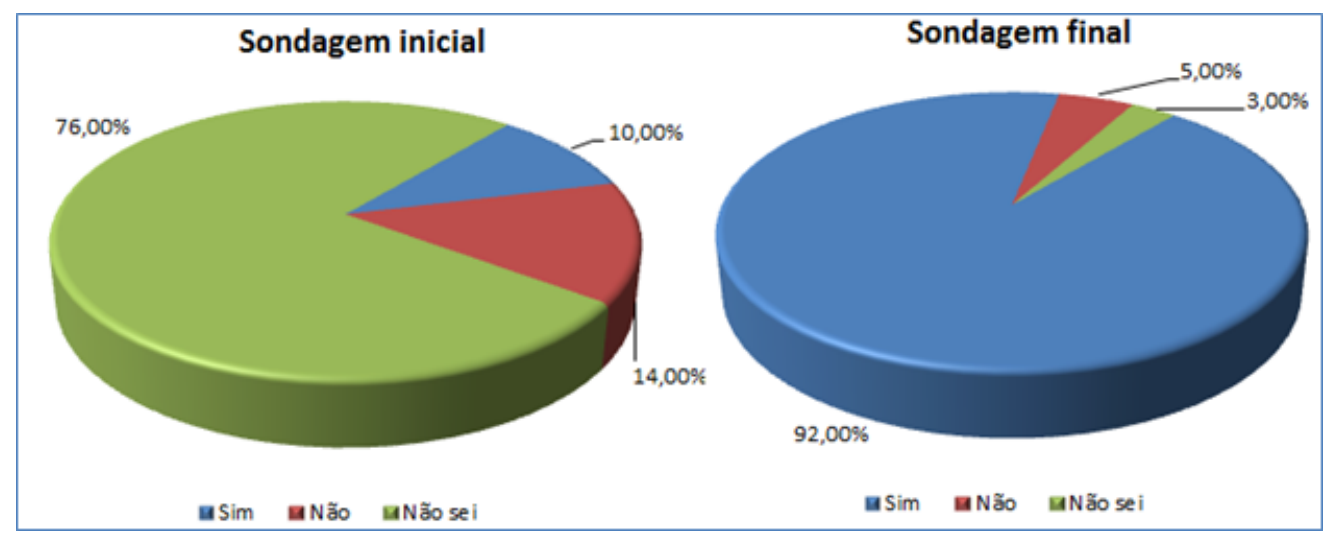

Figura 15: Toda a matéria conhecida é composta de léptons e quarks. Fonte: Elaborado pelos autores.

Sobre a constituição da matéria, verificou-se na sondagem inicial que $76 \%$ dos alunos não sabiam a resposta. Já após o desenvolvimento do projeto e aplicação da sondagem final, verifica-se que $92 \%$ dos alunos afirmaram que sim, a matéria é composta por léptons e quarks.

Os dados coletados com a aplicação da sondagem inicial demonstraram que os alunos apresentavam pouco conhecimento sobre conceitos relativos às partículas elementares, isso fica evidente ao analisar as figuras 8 a 15. No entanto, as informações levantadas foram importantes para identificar os subsunçores presentes na estrutura cognitiva dos alunos, para, a partir daí, delimitar o escopo da pesquisa.

\section{Análise do questionário de opinião}

Após a sondagem final aplicou-se um questionário que visou verificar o grau de satisfação dos alunos com o desenvolvimento da UEPS.

A primeira pergunta questionou o grau de satisfação do aluno com as atividades desenvolvidas ao longo do projeto. O consolidado das respostas obtidas seguem na figura 16.

Ao analisar os dados obtidos na primeira pergunta do questionário de opinião, verificouse um alto nível de satisfação em relação às atividades desenvolvidas ao longo do trabalho, este fato evidencia-se ao verificar que o somatório dos alunos satisfeitos a totalmente satisfeitos chegou a $90 \%$. 


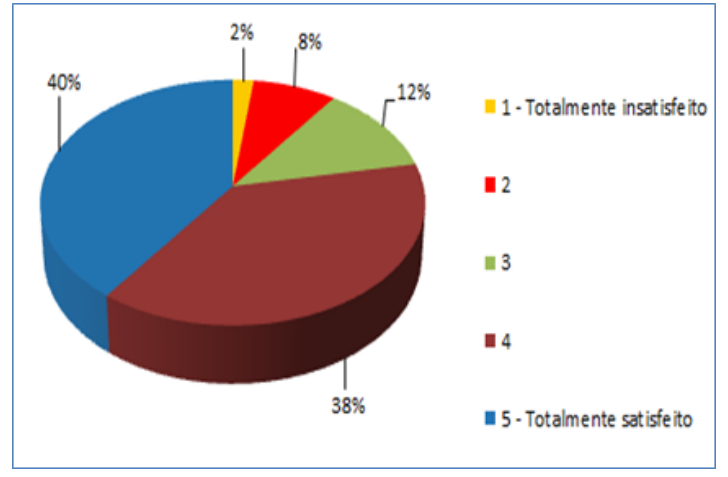

Figura 16: Qual é o seu grau de satisfação com as atividades desenvolvidas ao longo do projeto? Fonte: Elaborado pelos autores.

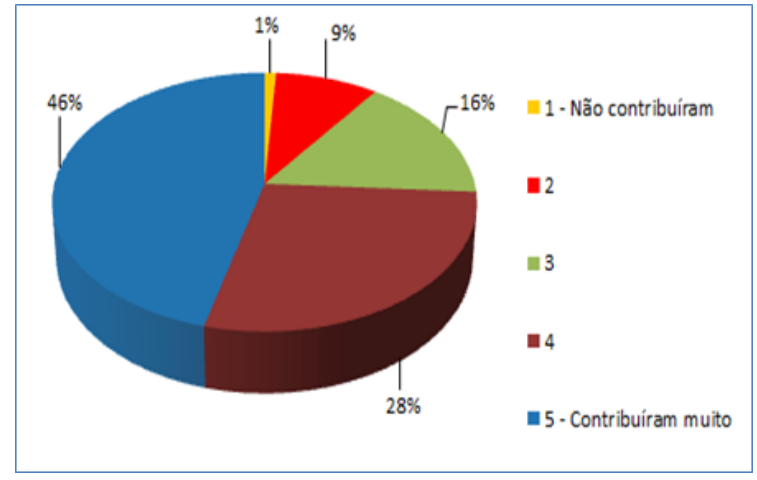

Figura 17: As atividades desenvolvidas contribuíram para a aprendizagem de novos conceitos? Fonte: Elaborado pelos autores.

Durante a realização da UEPS ficava evidente a motivação e empolgação dos alunos. Muitos se ofereciam para ajudar a preparar as aulas seguintes, outros buscavam em outras fontes, informações sobre o modelo padrão e partículas elementares. Algumas partículas foram descobertas durante a realização do projeto, e aqueles alunos mais atentos, logo noticiavam a descoberta para os demais colegas.

A segunda pergunta indagava se as atividades desenvolvidas contribuíram para a aprendizagem de novos conceitos. O consolidado das respostas obtidas segue na figura 17.

Ao serem indagados se as atividades desenvolvidas contribuíram para a aprendizagem de novos conceitos, $90 \%$ dos alunos afirmaram que as atividades contribuíram a contribuíram muito para a aprendizagem, demonstrando um alto nível de satisfação com as atividades desenvolvidas.

$\mathrm{Na}$ terceira pergunta os alunos deveriam responder qual era o seu nível de ansiedade em relação às próximas aulas do projeto. A figura 18 apresenta um consolidado das respostas obtidas.

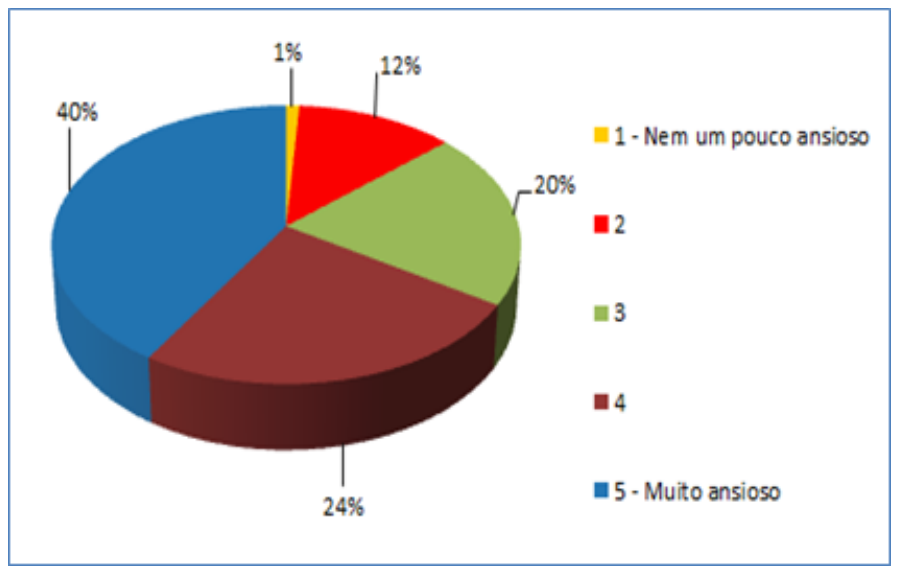

Figura 18: Qual era o seu nível de ansiedade em relação às próximas aulas do projeto? Fonte: Elaborado pelos autores.

Com o intuito de verificar se os alunos mantinham-se ansiosos para os próximos encontros, perguntou-se qual era o nível de ansiedade deles em relação às próximas aulas e $84 \%$ 
afirmaram que permaneciam a permaneciam muito ansiosos para os próximos encontros.

\section{CONSIDERAções Finais}

Neste trabalho buscou-se ensinar conceitos básicos de Física de Partículas a partir de uma Unidade de Ensino Potencialmente Significativa que se utilizou de jogos de cartas baseados no modelo padrão e nas interações fundamentais. A escolha da metodologia apresentada por Moreira (2011) foi de grande valia, pois esclareceu de forma prática como elaborar e aplicar as atividades de acordo com os princípios da Teoria da Aprendizagem Significativa de Ausubel, levando o professor a refletir sobre as etapas e as atividades desenvolvidas, considerando o conhecimento trazido pelos estudantes.

A partir da análise dos dados coletados, notou-se indícios de aprendizagem significativa. Os estudantes sentiram-se motivados a participar das atividades e destacaram a relevância de se usar elementos diferenciados e significativos em sequências didáticas.

Avaliando a aprendizagem na UEPS, percebe-se boa evolução em torno dos conceitos envolvendo principalmente o Big Bang, os aceleradores de partículas, o modelo padrão e as interações fundamentais.

A partir da análise dos dados coletados neste trabalho, conclui-se que as atividades aplicadas nesta pesquisa foram capazes de tornar o assunto mais interessante para os estudantes (figuras 16, 17 e 18), principalmente aquelas que envolveram os jogos de cartas. Também é possível concluir que bons resultados de aprendizagem foram obtidos, principalmente em torno dos conceitos de partículas elementares e interações fundamentais (figuras 8, 9, 10, 13, $14,15)$. Também houve aumento na compreensão do funcionamento dos aceleradores de partículas (gráficos 11, e 12).

Desta forma, os objetivos relacionados à elaboração e aplicação da Unidade de Ensino Potencialmente Significativa UEPS proposta neste trabalho foram atingidos. A análise dos dados obtidos na pesquisa reforça a hipótese de que a abordagem de jogos no contexto educacional juntamente com outras atividades como: pesquisas, discussões e explanações, pode facilitar o ensino de conceitos básicos de Física Moderna e nesse caso, em especial, conceitos de Física de Partículas e Interações Fundamentais.

Por fim, vale ressaltar que a aplicação dos jogos se deu de forma pedagógica e não somente como uma disputa. Para tanto, o professor estava sempre presente, observando e intervindo quando necessário, de forma que os alunos realmente aplicassem os conceitos discutidos anteriormente durante as aulas.

\section{REFERÊNCIAS}

AUSUBEL, D. P. Educational psychology: A cognitive view. Nova York, Holt, Rinehart and Winston Inc., 1968.

AUSUBEL, D.P.; NOVAK, J.D.; Hanesian, H. (1978). Educational psychology: a cognitive view. 2nd. ed. New York, Holt Rinehart and Winston.

. Psicologia educacional. 2ed., Rio de Janeiro: Interamericana. 625p, 1980. 
AUSUBEL, D. P. Aquisição e Retenção do Conhecimento: Uma perspectiva cognitiva. Platano. Rio de Janeiro, 2003. Disponível em: <http:/ /www.scielo.br/scielo.php?script=sci_nlinks\& ref=000156\& pid=S1519-7077201100030000700008\& lng=pt $>$. Acesso em: 11. Mar 2018.

BRASIL. Parâmetros Curriculares Nacionais para o Ensino Médio. Ministério da educação. Secretária da Educação Média e Tecnológica. Brasília, 1999.

. MEC. Secretaria de Educação Média e Tecnológica. PCNs+ Ensino Médio: orientações educacionais complementares aos Parâmetros Curriculares Nacionais. Brasília, 2002. 141 p.

BRUHNS, H. T., O jogo parceiro e o jogo adversário. 2a ed. Campinas: Papirus, 1999.

CAVELLUCCI, L. C. B. Estilos de aprendizagem: em busca das diferenças individuais. Campinas: Ed. da Unicamp, 2003. Disponível em: <http:/ /www.iar.unicamp.br/disciplinas / am540_2003/lia/estilos_de_aprendizagem.pdf>. Acesso em: 20 mar. 2018.

. Mapas conceituais: uma breve revisão. [S.1.: s.n.], [2009?].

GONZALES,E. G.; ROSA, P. R. S. Aprendizagem significativa de conceitos de circuitos elétricos utilizando um ambiente virtual de ensino por alunos da educação de jovens e adultos. Revista Investigações em Ensino de Ciências IENCI, v. 19, n. 2, 2014. Instituto de Física. Universidade Federal do Rio Grande do Sul UFGRS. 2014. Disponível em: <https://www.if.ufrgs.br/cref/ojs/index.php/ienci/article/view/91>. Acesso em: 10 mar. 2018.

LEMOS, E. D. S. A aprendizagem significativa: estratégias facilitadoras e avaliação. Aprendizagem Significativa em Revista, v. 1, n. 1, p. 25-35, 2011. Disponível em: <http://www.if.ufrgs.br/asr/artigos/Artigo_ID3/v1_n1_a2011.pdf>. Acesso em: 11 mai. 2018.

MENEZES, L. C. (Coord). Parâmetros curriculares nacionais: ensino médio. Parte III Ciências da natureza, matemática e suas tecnologias. Brasília: Ministério da Educação, 1996. Disponível em: <http:/ / portal.mec.gov.br/seb/arquivos/pdf/ciencian.pdf>. Acesso em: 01 mar. 2018.

MOREIRA, M. A. Mapas conceituais e aprendizagem significativa. Porto Alegre: UFRGS, 1997. Disponível em: <http://www.if.ufrgs.br/ moreira/mapasport.pdf>. Acessado em: 24 abr. 2018.

. Teorias de Aprendizagem. Editora Pedagógica Universitária, São Paulo, 1999.

Partículas e Interações. Física na Escola. São Paulo. Vol. 5, n. 2 (out. 2004), p. 10-14, 2004. Disponível em: <http:/ / www.sbfisica.org.br/fne/Vol5/Num2/v5n1a03.pdf>. Acesso em: 01 mar. 2018.

O Modelo Padrão da Física de Partículas. Revista Brasileira de Ensino de Física. [online]. 2009, vol.31, n.1, pp.1306.1-1306.11. ISSN 1806-1117. Disponível em: <http:/ / www.scielo.br/scielo.php?pid=S1806-11172009000100006\& script=sci_abstract\& tlng=pt $>$. Acesso em: 09 mar. 2018. 
. Unidades de Ensino Potencialmente Significativas-UEPS. 2011. Disponível em: <https: //www.if.ufrgs.br/ moreira/UEPSport.pdf>. Acesso em: 03 mar. 2018.

MOREIRA, M. A.; MASINI, E. F. S. Aprendizagem significativa. A teoria de David Ausubel. Ed. Centauro. São Paulo, 2001.

MOREIRA, M.A.; SOUSA, C.M.S.G. (1996). Organizadores prévios como recurso didático. Porto Alegre, RS, Instituto de Física da UFRGS, Monografias do Grupo de Ensino, Série Enfoques Didáticos, nř 5 .

MOREIRA, M. A.; OSTERMANN, F. Teorias construtivistas. Porto Alegre: UFRGS, 1999.

NOVAK, J. D.; GOWIN, D. B. Aprendiendo a aprender. Barcelona: Martínez Roca, 1988. Disponível em: <http://www.terras.edu.ar/biblioteca/3/EEDU_NovakGowin_Unidad_1(1).pdf>. Acesso em: 30 mai. 2018.

OSTERMANN, F. e CAVALCANTI, C.J.H. (2001). Um pôster para ensinar Física de Partículas na escola. Física na Escola. v.2, n.1, p.13-18. Disponível em: <http://www1.fisica.org.br/fne/index.php/edicoes/category/36-volume-02-n-1-maio>. Acesso em: 11 mar. 2018.

Teorias de aprendizagem. Instituto de Física, Porto Alegre: Evangraf. Universidade Federal do Rio Grande do Sul. Porto Alegre, 2011. Disponível em: <http://www.ufrgs.br/sead/servicos-ead/publicacoes-1/pdf/Teorias_de_Aprendizagem.pdf>. Acesso em: 31 mai. 2018.

RORATTO, C.; NOGUEIRA. C. M. I.; KATO, L. A. Ensino de Matemática, História da Matemática e aprendizagem significativa: uma combinação possível. Revista Investigações em Ensino de Ciências IENCI, v. 16, n.1, 2011. Instituto de Física. Universidade Federal do Rio Grande do Sul UFGRS. 2011. Disponível em: <https://www.if.ufrgs.br/cref/ojs/index.php/ienci/article/view/250/175>. Acesso em: 27 mai. 2018.

SIQUEIRA, M. R. P., Do Visível ao Indivisível: uma proposta de Física de Partículas Elementares para o Ensino Médio. 2006. 257f. Dissertação (Mestrado em ensino de Ciências) - Universidade de São Paulo. Instituto de Física e Faculdade de Educação. 2006. Disponível em: < http: / / sites.usp.br/nupic/wp-content/uploads/sites/293/2016/05/DissertMAXWELL.pdf>. Acesso em: 11 mar. 2018.

TERRAZZAN, E. A., A inserção da Física Moderna e Contemporânea no Ensino de Física na escola de 20 grau. Caderno Catarinense de Ensino de Física. Florianópolis, V.9, n.3, p.209-214, dez.1992. Disponível em: <https://periodicos.ufsc.br/index.php/fisica/article/viewFile/7392/6785>. Acesso em: 11 mar. 2018. 


\section{A. QuestionÁRIO de VERIFICAÇÃo INICIAL}

Este questionário possui o intuito de verificar seus conhecimentos e concepções acerca das partículas elementares. Ao responder as afirmações você pode concordar (sim), discordar (não) ou pode afirmar não saber (não sei) nada a respeito da afirmação. O objetivo não é testar os seus conhecimentos sobre o assunto, mas sim, realizar um levantamento do que é conhecido por você no início e no final do projeto.

Nome: Turma:

\begin{tabular}{|l|l|l|l|}
\hline 1. O átomo é a menor estrutura conhecida e, portanto, é indivisível. & SIM & NÁO & $\begin{array}{c}\text { NÁO } \\
\text { SEI }\end{array}$ \\
\hline 2. Toda matéria comum é formada por quarks up, down e elétrons. & & & \\
\hline 3. A antimatéria é ficção científica e não um fato científico. & & & \\
\hline 4. O elétron é composto por partículas ainda menores. & & \\
\hline 5. A força eletromagnética é responsável por gerar a corrente elétrica. & & & \\
\hline 6. O trabalho feito nos aceleradores nos ajuda a compreender o universo. & & & \\
\hline 7. Das forças fundamentais da natureza, a gravidade é a mais forte. & & & \\
\hline 8. Toda a matéria conhecida é composta de léptons e quarks. & & & \\
\hline 9. Existem aceleradores de partículas no Brasil. & & & \\
\hline 10. Os acelerados de partículas podem criar buracos negros. & & & \\
\hline 11. Os prótons e nêutrons são compostos por quarks. & & & \\
\hline 12. O Bóson de Higgs é quem "da massa" a todas as outras partículas. & & & \\
\hline 13. As partículas originadas no Big Bang ainda estão presentes na Terra. & & & \\
\hline 14. Quarks e hádrons são partículas elementares. & & & \\
\hline 15. A força fraca é responsável pela atração gravitacional. & & & \\
\hline
\end{tabular}

Questionário de verificação inicial. 
B. Apresentação Sobre a definiçÃo E CONStrução de mapas CONCEITUAIS.

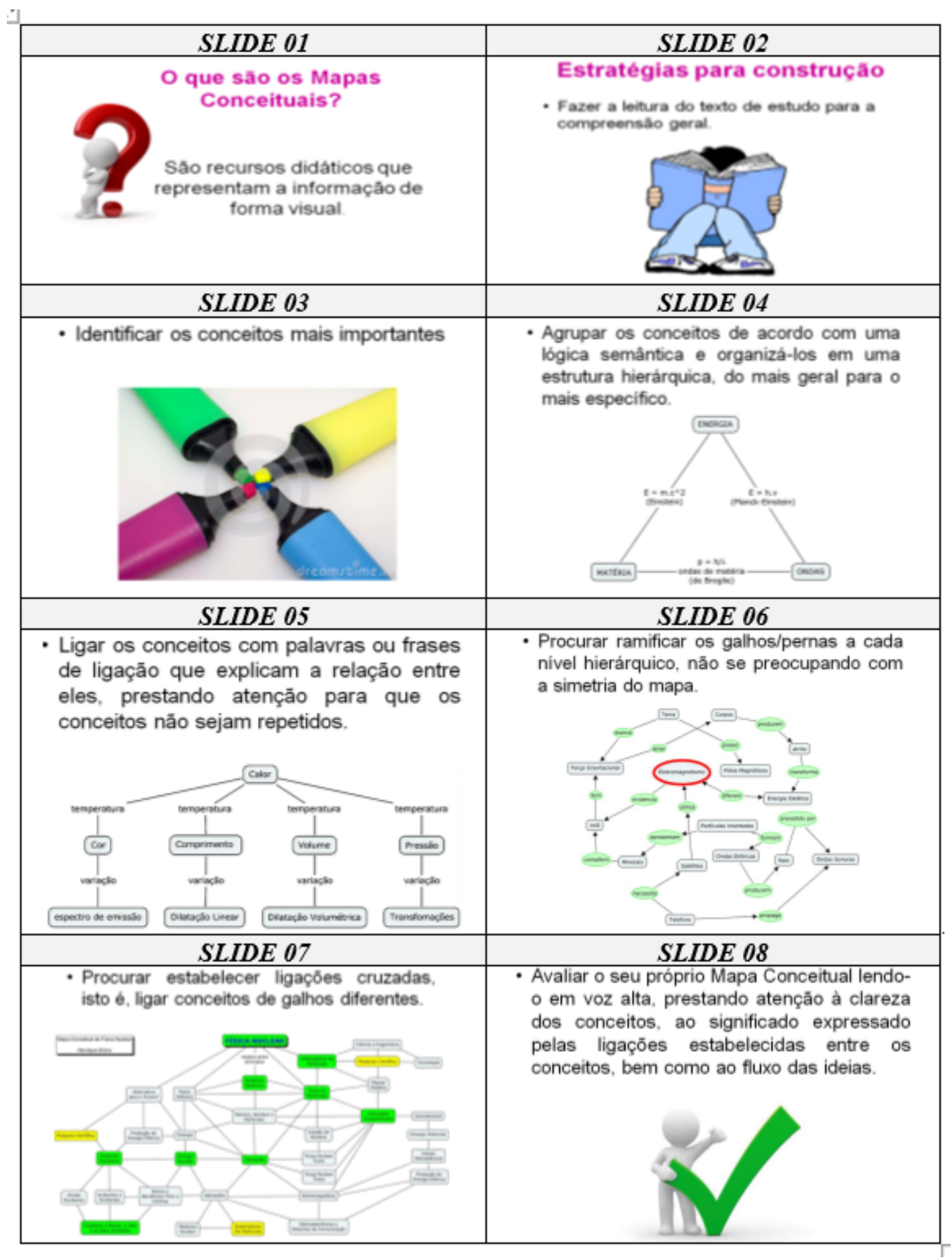




\section{ApresentaÇão SOBRE A DEFINIÇÃO E FORMAÇÃO DE HÁdRONS.}

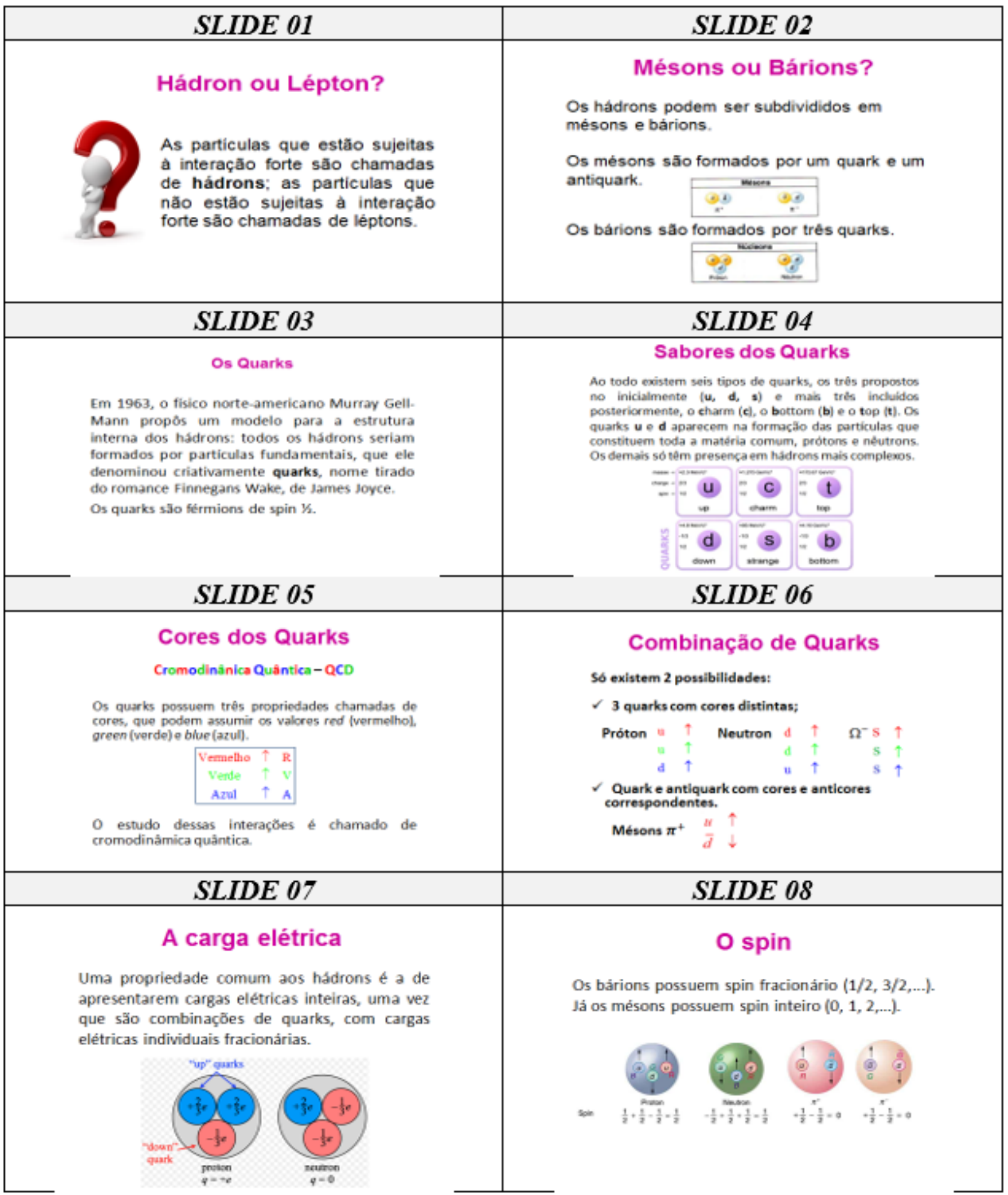




\section{Questionário DE VERIFICAÇÃo FINAL}

Este questionário possui o intuito de verificar seus conhecimentos e concepções acerca das partículas elementares. Ao responder as afirmações você pode concordar (sim), discordar (não) ou pode afirmar não saber (não sei) nada a respeito da afirmação. O objetivo não é testar os seus conhecimentos sobre o assunto, mas sim, realizar um levantamento do que é conhecido por você no início e no final do projeto.

\begin{tabular}{|l|l|l|l|}
\hline 1. O átomo é a menor estrutura conhecida e, portanto, é indivisível. & SIM & NÁO & $\begin{array}{c}\text { NÁO } \\
\text { SEI }\end{array}$ \\
\hline 2. Toda matéria comum é formada por quarks up e down e elétrons. & & & \\
\hline 3. A antimatéria é ficção científica e não um fato científico. & & & \\
\hline 4. O elétron é composto por partículas ainda menores. & & \\
\hline 5. A força eletromagnética é responsável por gerar a corrente elétrica. & & & \\
\hline 6. O trabalho feito nos aceleradores nos ajuda a compreender o universo. & & & \\
\hline 7. Das forças fundamentais da natureza, a gravidade é a mais forte. & & & \\
\hline 8. Toda a matéria conhecida é composta de léptons e quarks. & & & \\
\hline 9. Existem aceleradores de partículas no Brasil. & & & \\
\hline 10. Os acelerados de partículas podem criar buracos negros. & & & \\
\hline 11. Os prótons e nêutrons são compostos por quarks. & & & \\
\hline 12. O Bóson de Higgs é quem "da massa" a todas as outras partículas. & & & \\
\hline 13. As partículas originadas no Big Bang ainda estão presentes na Terra. & & & \\
\hline 14. Quarks e hádrons são partículas elementares. & & & \\
\hline 15. A força fraca é responsável pela atração gravitacional. & & \\
\hline
\end{tabular}

Questionário de verificação final. 


\section{E. Pesquisa de opinião}

Este questionário possui o intuito de avaliar o nível de satisfação com o desenvolvimento do projeto, possibilitando assim, uma melhoria nos processos desenvolvidos. Informe sua opinião e contribua com o aperfeiçoamento deste projeto.

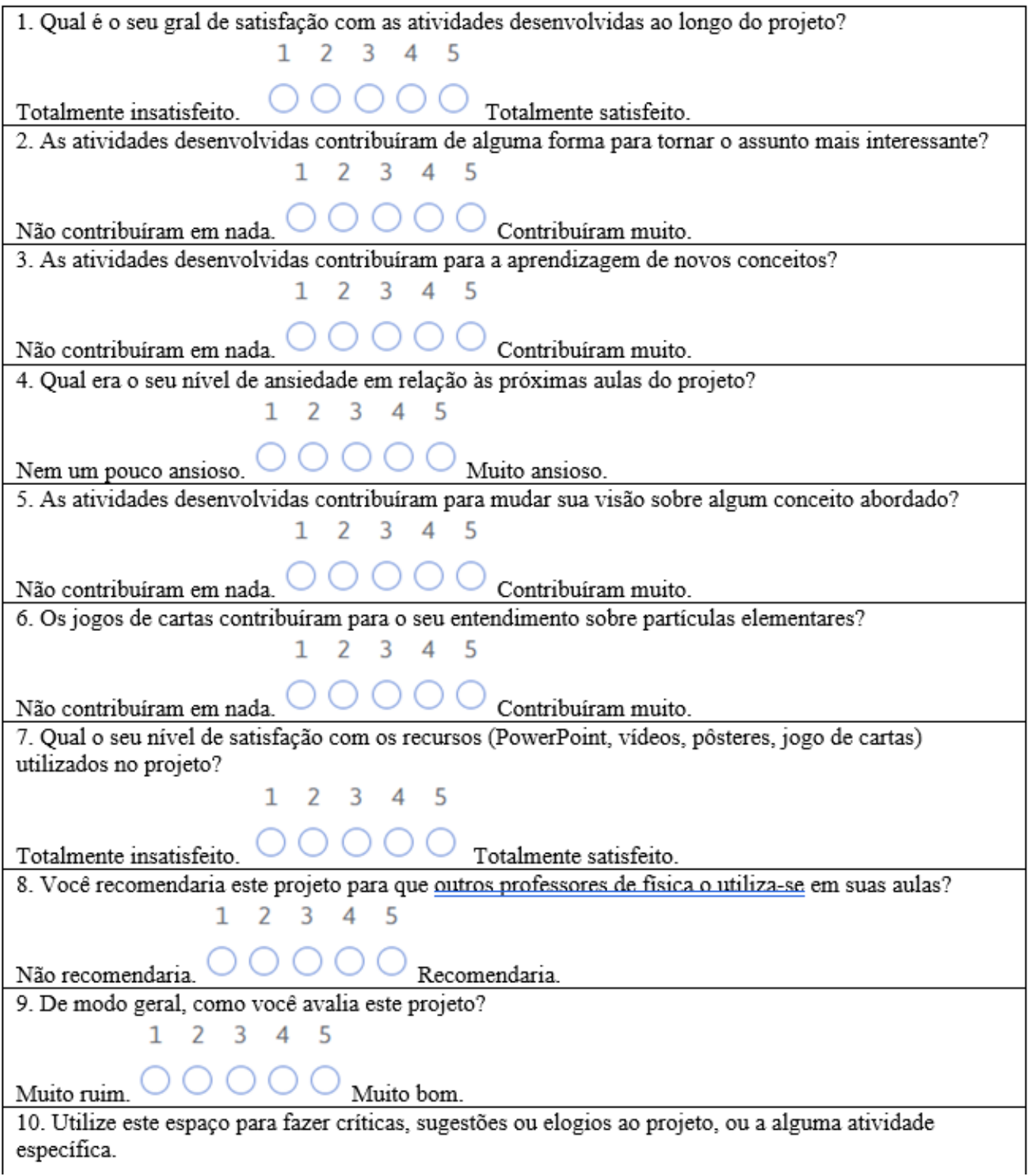

Pesquisa de opinião. 